D A V ID M. CUTLER

Harvard University and National Bureau of Economic Research

ELIZABETH RICHARDSON

Harvard University

\title{
Measuring the Health of the U.S. Population
}

VALUING THE HEALTH of the population is central to forming public policy for health care. It is frequently asserted that the marginal productivity of the medical system is low, so limiting overall medical spending would improve welfare.' But gauging the productivity of the medical sector requires measuring the output of the medical system, which cannot be done without valuing the health of the population. Similarly, resource allocations must often be made within the medical sector: Should more be spent on research for the young or the elderly? Should the focus be on prevention or cure? But these decisions cannot be made without knowing the output of medical spending - in short, its health consequences. A great deal has been written from the private perspective about changes in the distribution of wealth and income over the past several decades. ${ }^{2}$ But utility depends on health as well as consumption, and to capture the utility consequences of recent changes

We are grateful to the editors and to Victor Fuchs, Zvi Griliches, Larry Katz, Ted Keeler, David Meltzer, and Doug Staiger for helpful comments. This research was supported by grants to the National Bureau of Economic Research from the Bureau of Labor Statistics, the Bureau of Economic Analysis, the National Institutes on Aging, and Eli Lilly and Company.

1. This is implicit in the analysis of Chassin and others (1987), Cutler (1995), Cutler and Staiger (1996), Greenspan and others (1988), Kahn and others (1990), McClellan and Newhouse (1995), Newhouse and the Insurance Experiment Group (1993), Staiger and Gaumer (1994), Tu and others (1997), Winslow, Kosecoff, and others (1988), and Winslow, Solomon, and others (1988).

2. See Karoly and Burtless (1995) for a review. 
in the economy, health must be valued as well. ${ }^{3}$ Finally, the relationship between health and economic behavior is often of interest. Are the sick elderly more likely to retire than the healthy elderly? How is this relation changing over time? To answer these questions requires measuring health and its changes over time.

Despite the central importance of health to human welfare and the enormous role of the government in affecting people's health, little has been written systematically analyzing the health of the population or how it has changed. Many health facts are widely known: Infant mortality has fallen over time; the elderly are living longer than they used to; AIDS has become the leading cause of death for younger males. But how should these various factors be combined? What is the appropriate conceptual framework for valuing health?

These questions are not unlike the ones that faced Simon Kuznets in the middle of the century: Measures of output and prices were widely available, but it took his conceptual framework to integrate them all. ${ }^{4}$ This paper discusses an economic framework for measuring health and presents empirical estimates of the health of the population over the past thirty years.

We begin by introducing the notion of "'health capital,' developed by Grossman. ${ }^{5}$ We define health capital analogously to human capital. Where human capital is the present value of a person's lifetime productivity, ${ }^{6}$ health capital is the present value of a person's lifetime health.

Measuring health capital is difficult; "health" is a multiattribute concept, and not all of its attributes can be easily determined. For example, the health of a stroke survivor is affected not only by increased morbidity such as partial paralysis, but also by a decrease in emotional well-being associated with these changes. Measuring health is also complicated by changes in diagnosing illness over time. The increased use of psychotropic drugs in the treatment of certain mental illnesses has led to more frequent diagnoses of depression. Only measuring the

3. Deaton and Paxson (1997) show inequality measures for some components of health.

4. We are grateful to Zvi Griliches for suggesting this analogy.

5. Grossman (1972).

6. See Becker (1975). Note that the appropriate measure of productivity is "potential" productivity - the amount the person could earn at work. If the person chooses not to work, we do not want to value his or her human capital less. 
prevalence of reported depression over time leads to the conclusion that the prevalence of debilitating mental illness has increased, when in fact the opposite may have occurred. Finally, measures of health are difficult because certain conditions affect health in the future but have no immediate physical or mental manifestations. For example, people with hypertension are at increased risk of suffering an adverse cardiovascular event, but in the absence of such an event they are asymptomatic. In a lifetime sense, hypertensives are less healthy than nonhypertensives, but they may not report themselves that way. These issues require a particularly careful analysis of the available data.

We use a number of data sources to measure health. Some components of health can be analyzed using self-reported disease information (for example, whether the person has been hospitalized for a serious illness), and we use the annual National Health Interview Surveys to do so. Knowledge of some diseases requires longitudinal records of particular samples of people (for example, people with cancer); we make use of this information where it is available.

The simplest measure of health capital is the "years-of-life" (YOL) approach: Individuals who are alive are healthy, and individuals who are dead are not. Thus health capital for any person is just his or her expected future number of years alive, or life expectancy. Because mortality rates have been falling over time, the YOL measure of health capital has been rising. Under our benchmark estimates of the discount rate (3 percent a year) and the value of a year of life $(\$ 100,000)$, we estimate the increase in health capital for a newborn between 1970 and 1990 at $\$ 77,000$ per person and for a person aged 65 at $\$ 159,000$. These values are relatively high; the increase in average medical spending over the infant's lifetime, for example, is $\$ 19,000$, and the increase in average medical spending for an elderly person is $\$ 34,000$.

But not all years of life are valued the same. A year of good health is valued more than one with cancer, diabetes, or even arthritis. We define a second measure of health capital, termed the "quality-adjusted life year" measure (QALY), that accounts for morbidity as well as mortality. Quality of life is measured on a scale from 0 (death) to 1 (perfect health). Using data on individuals' assessments of their selfreported health status, we attach QALY weights to living with major chronic diseases and functional impairments. We then value qualityadjusted life years over time. Our measures of quality-adjusted health 
also increase over time. For a newborn, quality-adjusted health between 1970 and 1990 rose by $\$ 95,000$; for a person aged 65 , quality-adjusted health rose by $\$ 169,000$.

The changes in health capital are decomposed into three factors. First, as a result of mortality reductions, more people are living to older ages. Second, the prevalence of disease at any age is increasing because many of the "marginal survivors" will have survived a serious illness. Third, health conditional on having survived a serious illness is improving for both marginal and inframarginal survivors as medical care and social changes have made it easier to function with a disease than it was in the past. The first and third of these factors increase health; the second factor reduces it. On net, these three factors result in a health improvement of $\$ 100,000$ to $\$ 200,000$.

The fact that health capital improved more for the elderly than for the young is a direct result of the nature of health improvements over this time period. The most dramatic change in health in recent decades has been the reduction in cardiovascular disease mortality. Because this change largely affects the elderly, the gains to the elderly are larger (in a present value sense) than the gains to the young.

In the remainder of the paper, we discuss a framework for measuring the health of the population and present empirical estimates of changes in health over time. The first section discusses trends in health in the twentieth century. We then present a theoretical framework for measuring health capital. In the third section, health capital is estimated using the years of life approach. In the fourth and fifth sections, we develop the quality of life approach. The last section concludes.

\section{Trends in Health}

Before presenting a conceptual framework for measuring health, we set the stage for our analysis with some basic facts about health over the past century, particularly in the past fifty years.

The most fundamental measure of health is the length of life. Figure 1 shows age-adjusted aggregate mortality rates since 1900. Mortality has fallen dramatically in the twentieth century. In 1900 the death rate was 2,300 per 100,000 . By 1994 the death rate was 775 per 100,000 , a decline of 66 percent. 
Figure 1. Age-Adjusted Mortality in the Twentieth Century

Deaths per 100,000 population

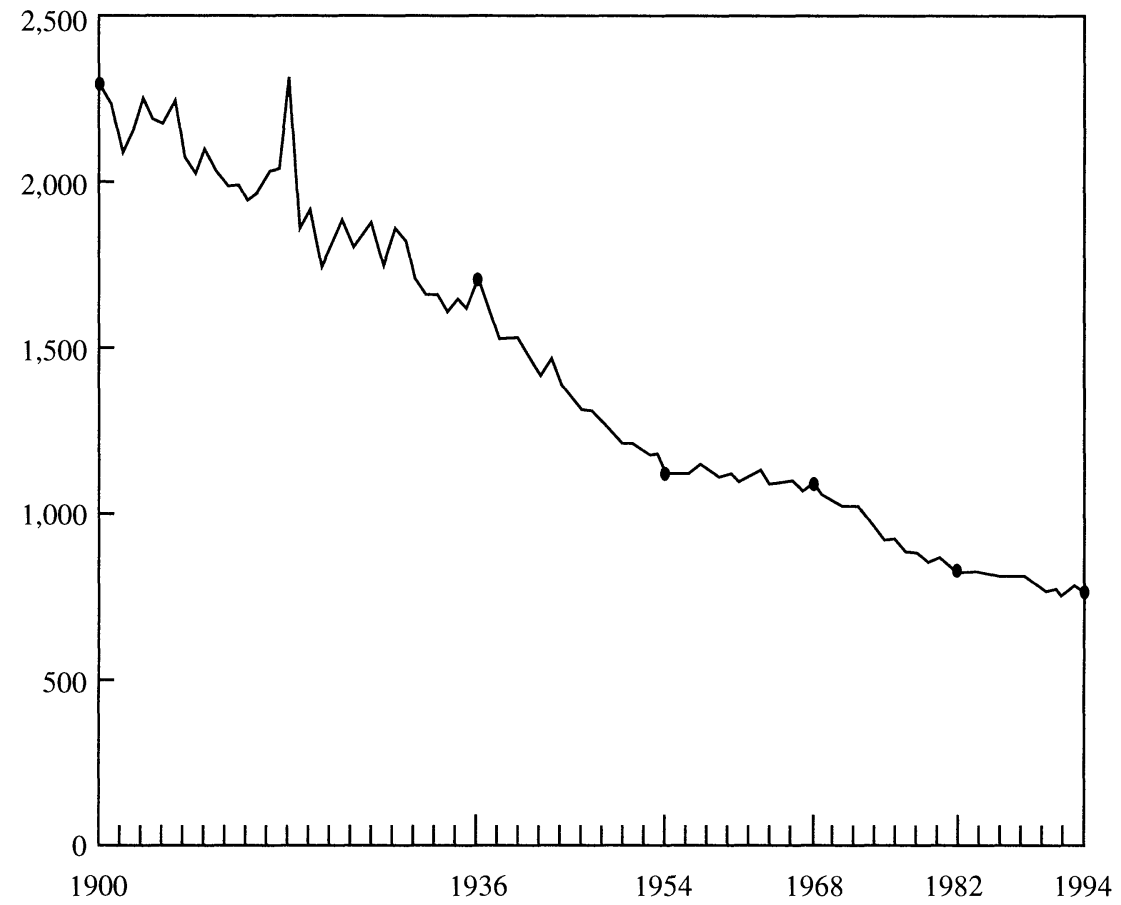

Source: Bell and Kumar (1996).

But the rate of mortality decline has not been uniform. Mortality fell moderately from 1900 to 1936 (0.8 percent a year), then fell extremely rapidly from 1936 to 1954 (2.3 percent a year). Between 1954 and 1968 mortality rates fell by only 0.2 percent a year. But just as it seemed that progress in improving health was nearing an end, mortality rates resumed their decline. Between 1968 and 1982, mortality rates fell by 2.0 percent annually, near the rate of the 1936 to 1954 period. Since 1982 mortality rates have declined less rapidly, by only 0.5 percent a year.

Mortality rates can fall for various reasons: diseases of early infancy may be prevented, accident rates for middle-aged adults may decline, or more adults may reach old age. Figures $2 \mathrm{a}$ and $2 \mathrm{~b}$ show life expectancy (roughly the inverse of mortality) at birth and at age 65. The 
Figure 2. Life Expectancy, 1900-90

A. AT BIRTH

Years

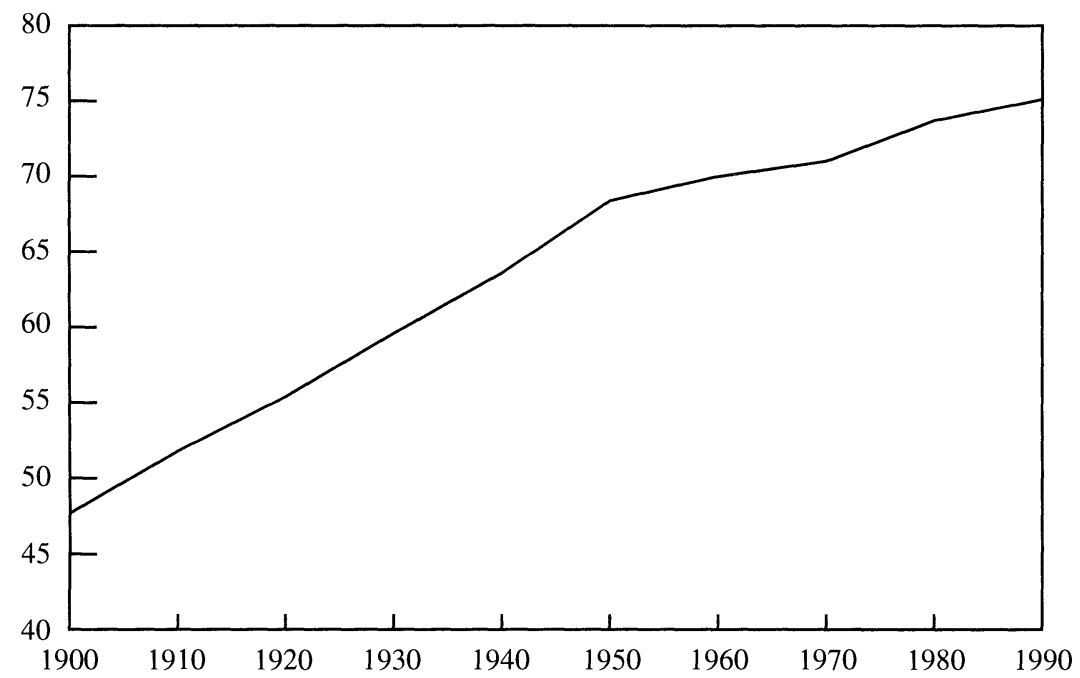

B. AT AGE 65

Years

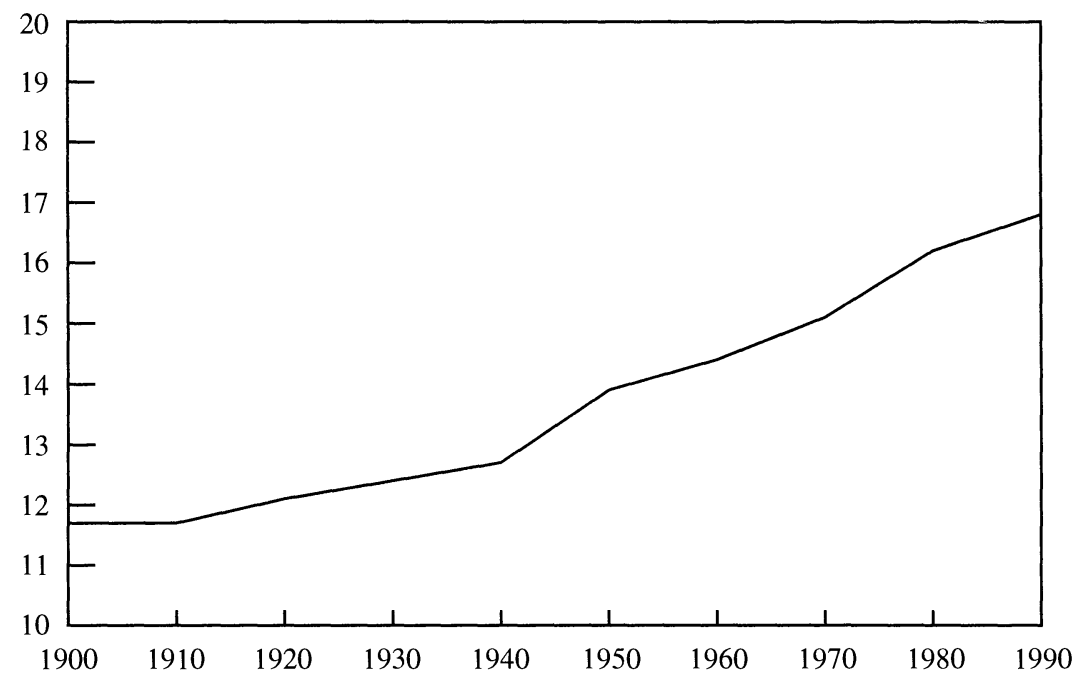

Source: Bell, Wade, and Gross (1992). 
twentieth century has been a mix of sources of mortality reductions. In the first half of the century, life expectancy increased primarily because infant mortality rates fell. Between 1900 and 1960, for example, life expectancy at birth increased by twenty-two years; life expectancy at age 65 increased by only three years. The predominant sources of mortality reduction were reduced deaths from diseases such as tuberculosis and influenza; these diseases were eradicated or substantially reduced by public health measures such as cleaner water and air and improved sanitation. ${ }^{7}$ These diseases typically affected newborns and infants, therefore this was where mortality fell most rapidly; only 5 percent of improved life expectancy at birth was accounted for by increased longevity beyond age 65 .

By the middle of the century, infant mortality rates were very low, and the prospects for further declines seemed limited. Tuberculosis, for example, was nearly eliminated, and death from infectious disease was cut substantially with the development of antibiotics. Awareness of this, coupled with the prospect of continuing high death from the chronic conditions of old age, led to pessimism about future mortality reductions. For example, Nobel laureate biologist René Dubos wrote, " Modern medicine has little to offer for the prevention or treatment of chronic and degenerative diseases that dominate the pathological picture of technologic societies.",

Dubos's projection proved inaccurate, however. After 1968 mortality not only began to decline again, but the decline was particularly concentrated in the older ages. Between 1960 and 1990, for example, life expectancy at birth increased by approximately 5 years and life expectancy at age 65 increased by approximately 2.5 years. Indeed, one-third of the increase in life expectancy at birth is accounted for by mortality improvements after age 65 .

Figure 3 shows more information about the sources of mortality decline since 1950. Mortality is divided into six causes: cardiovascular disease; cancer; infections; HIV; accidents, homicide and suicide; and other (diabetes, chronic obstructive pulmonary disease, kidney disease, and liver disease). ${ }^{9}$ The dominant contributor to the mortality decline

7. Preston and Haines (1991).

8. Dubos (1969), p. 328.

9. The gaps in the figure are years in which the International Classification of Disease 


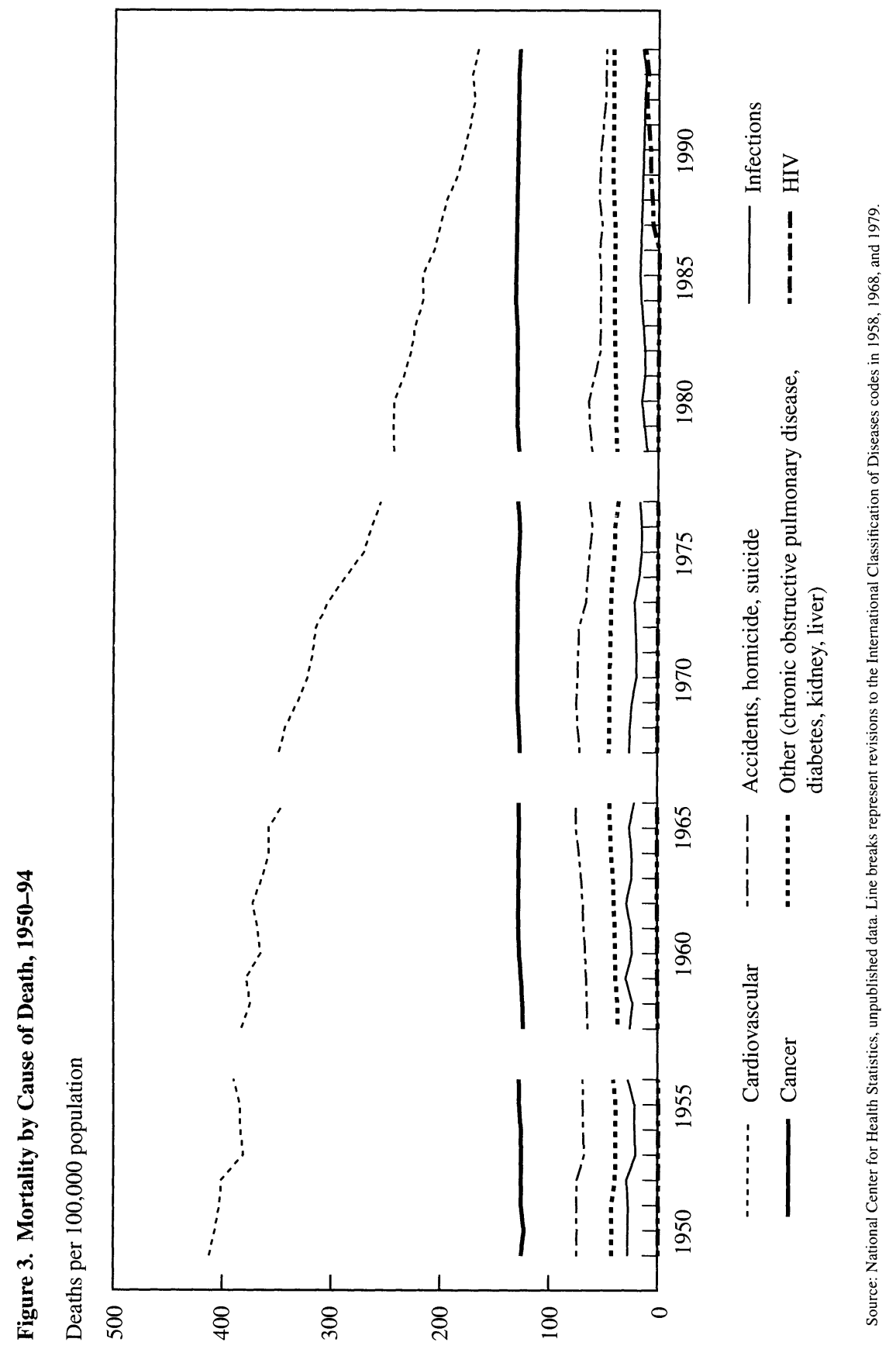


since 1950 has been reductions in cardiovascular disease mortality. Death from cardiovascular disease-coronary heart disease, stroke, atherosclerosis-has fallen by nearly 3 percent a year since 1968. In contrast, mortality from other chronic diseases - particularly cancerhas increased during this period, as has mortality from other causes such as AIDS. These latter facts explain why aggregate mortality reductions have been less rapid in the 1982-94 period than in the 1968-82 period. Because we are interested in health improvements primarily in the past half century, analysis here focuses extensively on cardiovascular disease.

Changes in morbidity are less clear than changes in mortality. On the one hand, some of the reduced mortality has been keeping sicker people alive, reducing health among the living. For example, although cardiovascular disease mortality has fallen by 3 percent annually since 1968, the incidence of severe cardiovascular incidents has fallen by only 1 percent annually. ${ }^{10}$ Thus the prevalence of cardiovascular disease in the surviving population is increasing. On the other hand, the incidence of other diseases-for example, tuberculosis or polio-has fallen dramatically. Furthermore, for many diseases the health consequence of having the disease is less severe than it used to be. People who survive a heart attack today, for example, are almost certainly better off than people who survived a heart attack fifty years ago.

Throughout the twentieth century, the reduction in disease incidence and improved functioning conditional on disease have dominated, and a pronounced decline in morbidity has occurred. One study documented substantially lower rates of chronic disease in World War II veterans in 1983 compared with Union Army veterans at roughly the same age in 1910. ${ }^{11}$ Musculoskeletal, digestive, circulatory, and respiratory disorders were one-half to one-fifth as prevalent in the later time period as in the earlier one.

Recent morbidity trends are more controversial. Data from the National Health Interview Surveys suggest that measures of activity limitations, self-reported health status, and the presence of chronic conditions all became worse in the 1970s but then improved in the 1980s.

codes changed. Data are not strictly comparable across gaps, but over long periods of time the impact of coding changes will be small.

10. Hunink and others (1997).

11. Fogel and others (1993). 
The increase in morbidity in the 1970s has been taken by some as evidence of worse health owing to an increased share of marginal survivors in the elderly population, ${ }^{12}$ but an alternative interpretation stresses measurement or reporting changes rather than true changes in health (see further discussion on this issue later). ${ }^{13}$

How much is the increase in health over the past forty years worth? We start with a simple calculation presaging our more detailed calculations later on. Between 1950 and 1990 life expectancy at birth rose from 68.3 to 75.0 years, a gain of 6.7 years. Because of reduced health at older ages, the marginal years of life added are assumed to be worth only 70 percent of the inframarginal years. Finally, a year of perfect health is assumed to be valued at $\$ 100,000$. Combining these terms, the net increase in the value of life between 1950 and 1990 is $\$ 469,000$ $(6.7$ years $\times 0.7 \times \$ 100,000)$.

This calculation is clearly an approximation. Determining what it approximates and how the numbers can be refined are the goals of this paper. The next section develops a theory that allows us to examine the health of the population.

\section{Health Capital: A Theoretical Approach}

Following Grossman, health capital is defined here as the utility resulting from the stock of current and future quality-adjusted life years. ${ }^{14}$ This measure of health capital is analogous to the theory of human capital. ${ }^{15}$ Human capital is the discounted value of the potential output of a person over time; health capital is the discounted value of the utility from health of a person over time. ${ }^{16}$

12. See Chirikos (1986), Colvez and Blanchet (1981), Crimmins (1990), and Verbrugge (1984).

13. Waidmann, Bound, and Schoenbaum (1995).

14. Grossman (1972).

15. Becker (1975).

16. Note that we could alternatively measure health capital in productivity termsas the stock of health that determines how productive a person is during his or her lifetime. Because we are interested in questions of the value of health more than its effect on economic output, we focus on a utility-based measure rather than a productionbased measure. 
Assume an individual's utility in year $t$ is a function $U_{t}=U\left(C_{t}, H_{t}\right)$ of consumption of goods and services that year $\left(C_{t}\right)$ and health $\left(H_{t}\right)$. Because no natural units for health exist, we are free to normalize it as desired. Following the literature, health is scaled from 0 (death) to 1 (perfect health). Living with various diseases falls somewhere between 0 and 1 . Health measured in this fashion is termed quality-adjusted life, and the sum of health over the lifetime is termed quality-adjusted life years, or QALYs. ${ }^{17}$ Assume utility is also 0 if the person is dead. ${ }^{18}$

Expected utility is the discounted value of annual utility over the person's potential life span. For a person of age $a$, this is

$$
V_{t}(a)=E_{t}\left[\sum_{s=0}^{\infty} \frac{U\left(C_{t+s}, H_{t+s}\right)}{(1+r)^{s}}\right]
$$

where both consumption and health are implicitly age dependent.

For each individual, utility depends on his or her own mix of health states and expectations about future health. If averaged over everyone in society, $V$ can be thought of as average utility for the population as a whole, given the average set of diseases and medical care received. ${ }^{19}$

A fundamental question in equation 1 involves what we are taking the expectation with respect to. Health depends on several factors: the diseases the person has had up to year $t$ and will have in the future (denoted $d_{t}=\left[d_{t-a}, d_{t-a+1}, \ldots, d_{t} ; \tilde{d}_{t+1}, \tilde{d}_{t+2}, \ldots\right]$, where $\sim \mathrm{s}$ signify future values); the medical care the person has had and will receive $\left(m_{t}\right)$; past and future consumption $\left(c_{t}\right)$; and past and future environmental factors including standard considerations, such as pol-

17. For an overview of the literature on quality-adjusted life years (QALYs), see Gold and others (1996).

18. People often simplify the utility function further by assuming that utility from health and goods consumption is multiplicative: $U=H^{*} U(C)$. This naturally captures the point that utility is zero if health is zero. We prefer the more general specification, however. Our formulation is not completely general because it assumes that changes in health do not affect the marginal rate of substitution between different goods. This is clearly not right (the disabled will not benefit from some services as much as the nondisabled), but the assumption seems reasonable.

19. This is not quite right because average utility is not the same as utility for the average person. But this assumption simplifies the theoretical analysis greatly. Because we ultimately work with linear approximations to utility functions, this issue is not central to our analysis. 
lution, as well as social factors, such as whether buildings have ramps for the disabled, and so on $\left(e_{t}\right)$.

Expected utility requires some assumptions about the future path of these variables. To understand individual decisionmaking, it is natural to use individual expectations about likely changes in the economic and social environment. ${ }^{20}$ But we are interested in a different question: understanding how changes in behavioral and environmental factors affect utility. For these purposes, we want to hold constant individual and environmental factors and then evaluate the effect of changes in these variables.

Specifically, what has been the effect of changes in disease prevalence, medical care, the environment, and individual lifestyle decisions on individual utility over time? Start from year $t$ and assume that individual and environmental factors remain constant from year $t$ on. The implied path of diseases is denoted as $d_{t, t}\left[d_{t, t}=\left(d_{t-a}, d_{t-a+1}, \ldots\right.\right.$, $\left.\left.d_{t} ; d_{t}, d_{t}, \ldots\right)\right]$, and the same for the other variables. Then, expected utility in year $t$ is

$$
V_{t, t}(a)=E_{t}\left[\sum_{s=0}^{\infty} \frac{U\left(C_{t+s}, H_{t+s}\right)}{(1+r)^{s}} \mid d_{t, t}, m_{t, t}, c_{t, t}, e_{t, t}\right] .
$$

If we reevaluate expected utility in year $t+k$, given the new individual and environmental factors in that year, expected utility in year $t+k$ will be

$$
\begin{aligned}
& V_{t+k, t+k}(a)= \\
& E_{t}\left[\sum_{s=0}^{\infty} \frac{U\left(C_{t+k+s}, H_{t+k+s}\right)}{(1+r)^{s}} \mid d_{t+k, t+k}, m_{t+k, t+k}, c_{t+k, t+k}, e_{t+k, t+k}\right] .
\end{aligned}
$$

The effect of changes in individual and environmental factors between period $t$ and period $t+k$ is $\Delta V_{t, t+k}(a)=V_{t+k, t+k}(a)-V_{t, t}(a)$. We can express the linear approximation to this change in utility (so that the marginal utilities of consumption and health are constant) as

20. Or, more accurately, the distribution of individual expectations if individual choices depend on more than the mean. 


$$
\begin{gathered}
\Delta V_{t, t+k}(a)=U_{c} \cdot \sum_{s=0}^{\infty} \frac{\left(C_{t+k+s}-C_{t+s}\right)}{(1+r)^{s}}+U_{H} \\
\cdot\left\{E_{t+k}\left[\sum_{s=0}^{\infty} \frac{H_{t+k+s}}{(1+r)^{s}} \mid d_{t+k, t+k}, m_{t+k, t+k}, c_{t+k, t+k}, e_{t+k, t+k}\right]\right. \\
\left.-E_{t}\left[\sum_{s=0}^{\infty} \frac{H_{t+s}}{(1+r)^{s}} \mid d_{t, t}, m_{t, t}, c_{t, t}, e_{t, t}\right]\right\} .
\end{gathered}
$$

The first term is the change in consumption (for simplicity we assume this is known with certainty). The second term is the change in the value of health. Both are measured in utils. Dividing through by the marginal utility of consumption, the change in utility in dollars (omitting the terms of the expectation) can be expressed as: ${ }^{21}$

$$
\begin{aligned}
& \frac{\Delta V_{t, t+k}(a)}{U_{c}}=\sum_{s=0}^{\infty} \frac{\left(C_{t+k+s}-C_{t+s}\right)}{(1+r)^{s}} \\
& +\left(\frac{U_{H}}{U_{c}}\right) \cdot\left\{E_{t+k}\left[\sum_{s=0}^{\infty} \frac{H_{t+k+s}}{(1+r)_{s}}\right]-E_{t}\left[\sum_{s=0}^{\infty} \frac{H_{t+s}}{(1+r)^{s}}\right]\right\} .
\end{aligned}
$$

Note that $U_{H} / U_{C}$ is the marginal rate of substitution between health and other goods and services. If health is valued in life years, it is the dollar value of an additional life year in perfect health.

The second term in equation 5-the health component of changes in the dollar value of utility over time-is defined as the change in health capital:

$$
\Delta \text { Health }_{\text {Capital }}{ }_{t,+k}(a)
$$

$$
=\left(\frac{U_{H}}{U_{c}}\right) \cdot\left\{E_{t+k}\left[\sum_{s=0}^{\infty} \frac{H_{t+k+s}}{(1+r)_{s}}\right]-E_{t}\left[\sum_{s=0}^{\infty} \frac{H_{t+s}}{(1+r)^{s}}\right]\right\} .
$$

Equation 6 is the fundamental equation of this paper. It states that the change in health capital over time can be decomposed into two terms: the change in the (discounted) number of quality-adjusted life

21. Note that this is similar to cost-benefit analysis for medical interventions: individuals are better off if the value of health improvements is greater than the reduction in consumption required to produce those health improvements, in short, if $\Delta V(a)$ is positive. See Cutler and others (1996) for more discussion. 
years times the dollar value of those life years. Neither of these terms is easy to measure, but we make an attempt at both.

In addition to the change in health capital, we may also care about its level. This is less easy to measure because we are less willing to make linearity assumptions for the utility function as a whole than we are for marginal changes in health or consumption. Still, assuming all years of life are valued the same, the level of health capital is given by

$$
\text { Health Capital, }(a)=\left(\frac{U_{H}}{U_{c}}\right) \cdot E_{t}\left[\sum_{s=0}^{\infty} \frac{H_{t+s}}{(1+r)^{s}}\right] .
$$

This is just the product of the number of quality-adjusted life years remaining times the value of those life years.

Because people have lived different amounts of time, it is not obvious how to compare health capital across ages. For example, a 50-year-old today might consume more health over his lifetime than an infant born today, but the 50-year-old's remaining health capital might be smaller. For this reason, we do not focus a great deal on the level of health capital across ages. But it is relevant to ask whether health capital has increased more for people of some ages compared with people of another age. Provided past factors that influence future health have been controlled for adequately, the change in health capital will indicate how changes in the economy are affecting different people.

A related issue concerns measuring average health capital for everyone of a particular age. Suppose that more 50-year-olds are alive than used to be alive and the marginal survivors are in worse health than the inframarginal survivors, whose health has not changed. Averaging health capital over the 50-year-olds who are alive shows that average health capital is falling, when in fact everyone is the same or better off. The solution to this paradox is to average health capital over the number of people potentially alive, not the number actually alive. The average over potential survivors (including zeros for those who are dead) will rise whenever health for every person has increased or stayed the same.

\section{Measuring Health Capital I: The Years-of-Life Approach}

Calculating health capital empirically requires measuring qualityadjusted life years over time, valuing those years in dollars, and dis- 
counting them to the present, a formidable task. To simplify, we start by defining quality-adjusted life as a binary variable for life or death (everyone alive has $H=1$ and everyone dead has $H=0$ ), and equation 6 reduces to $^{22}$

\section{Health Capital, (a)}

$$
=\left(\frac{U_{H}}{U_{c}}\right) \cdot\left[\frac{\text { Alive }_{t}(a)}{\operatorname{Born}(t-a)}\right] \cdot\left[\sum_{s=0}^{\infty} \frac{\operatorname{Pr}\left(\text { Alive }_{t+s}\right)}{(1+r)^{s}} \mid \text { Alive }_{t}\right] .
$$

where $\operatorname{Pr}\left(\right.$ Alive $\left._{t+s}\right)$ is the probability that the person is alive at time $t+s$. The third term is years of expected life for those who are alive in year $t$; the second term is the share of people potentially alive in year $t$ who are actually alive. Thus the product of the two is expected future life years among those potentially alive in year $t$. If a discount rate of 0 is assumed, the last term in equation 8 is just life expectancy conditional on reaching age $a$.

\section{Measuring Survival}

The first question is what assumption to make about future survival probabilities. Two methods are frequently used to compute life tables, but neither one is ideal here. One is the period approach, which uses cross-section mortality rates to estimate life expectancy. The period approach may miss some of the effect of past health behaviors on future health. For example, if 50-year-olds today are healthier than 50-yearolds were twenty years previously (perhaps because they smoke less), they will likely have lower mortality rates when they reach age 70 than current 70-year-olds do. This will not show up in the period approach. The alternative is a cohort approach, a life table constructed by following the same cohort over time. This measure captures the effect of changes in past behavior on future mortality, but it also captures future changes in medical care or behavior that affect longevity. We do not want to include these changes in our analysis.

Deciding which life table to use is not easy. Because conducting cohort analysis requires many years of ex post data, which are not available, and because we believe medical technology advances may

22. This becomes a better approximation for the complete measure of health capital because the value of life in any state becomes much greater than the value of death. 
have had a large effect on quality-adjusted life over time, we use period life tables. We acknowledge the potential errors in this measure but do not attempt to correct them.

\section{The Value of Life}

In addition to measuring years of life, we need to value them in dollars. The value of a quality-adjusted life year is a subject of much debate. ${ }^{23}$ Two general approaches to measuring the value of life are used. One approach measures the value of life implicitly through revealed preference for risk. One can observe a market setting involving a trade-off between money and risk of death and impute the value an individual places on life. Examples of observed trade-offs include wage premiums for jobs involving a risk of death ${ }^{24}$ and the purchase of safety devices such as smoke detectors. ${ }^{25}$

Alternatively, the second approach directly elicits the value of a life using contingent valuation. Individuals are asked how much they are willing to pay for a hypothetical reduction in risk (or willing to accept in compensation to forgo the benefit), such as a particular treatment for a disease or removal of an environmental risk. Several issues need to be considered with contingent valuation, such as how the questions should be structured (for example, open-ended versus a series of discrete choices); whose willingness to pay should be elicited (for example, should family members' willingness to pay be included in valuing a drug treatment); and how to incorporate the fact that willingness to pay may vary with income, age, and time. Contingent valuation is widely used in cost-benefit analysis, however, particularly in environmental and health-related studies. ${ }^{26}$

Tolley and others synthesize the literature on valuing life and life years and conclude that a range of $\$ 70,000$ to $\$ 175,000$ per life year is reasonable. ${ }^{27}$ The analysis here assumes a benchmark value of $\$ 100,000$

23. See Viscusi (1993) for a review.

24. For example, see Moore and Viscusi (1988).

25. For example, see Dardis (1980).

26. See Neumann and Johannesson (1994), O'Brien and Viramontes (1994), and Johannesson (1996), among others, for examples and further discussion of the methodology.

27. Tolley and others (1994). 
per life year. One attractive feature of this analysis is that it is straightforward to change the value of a life year.

We do not vary the $\$ 100,000$ across people, age, or time because the rationale for doing so is controversial. For example, one might think that older people have lower value than younger people because they are on average less healthy. But this is a statement about the health of older people, not the value of a year in a given health status, so this consideration is not relevant.

The value of a year of perfect health might vary across people for other reasons, however. Society has invested more in some people than in others, and some contribute more back to society than others. Thus the value of a life year might be varied with the amount one contributes to society or that society has invested in a person. For example, the literature on disability-adjusted life years assumes that society values young adults more than children or older adults, but there is no variation by other factors such as income or the number of dependents an individual is supporting. ${ }^{28}$ The type of weights to use and specific values to employ are questions about the social welfare function. Because a standard social welfare function does not exist, the choice of weights in this context does not have a clear theoretical rationale. We assume, then, that the $\$ 100,000$ value of a life year is constant across people.

The value of life could also be varied over time. As society grows richer, the value of additional health might increase. The literature on the value of life is generally silent about how that value has changed over time, however. We thus assume the $\$ 100,000$ value of a life year is in 1990 dollars and has not changed over time.

\section{The Discount Rate}

The final issue to address is what discount rate to use, which is also a venerable issue in economics. ${ }^{29}$ The appropriate discount rate is the rate that trades off utility in different years. Although market interest rates are very high (as high as 7 to 8 percent in real terms), these are discount rates for dollars in different years, not utility. Market interest

28. Murray and Lopez (1996). This is based on the empirical observation that many people express a preference for saving the lives or life years of middle-aged people more than the very young or very old. The exclusion of other criteria in valuing people is made on a priori grounds.

29. See Atkinson and Stiglitz (1980) for discussion. 
Table 1. Health Capital by Age

(thousands of dollars)

\begin{tabular}{|c|c|c|c|c|c|c|c|}
\hline \multirow[b]{2}{*}{ Age } & \multicolumn{5}{|c|}{ Year } & \multicolumn{2}{|c|}{ Change } \\
\hline & 1950 & 1960 & 1970 & 1980 & 1990 & $1950-70$ & $1970-90$ \\
\hline 0 & 2,768 & 2,800 & 2,823 & 2,874 & 2,900 & 55 & 77 \\
\hline 20 & 2,407 & 2,452 & 2,473 & 2,546 & 2,580 & 66 & 107 \\
\hline 45 & 1,630 & 1,693 & 1,727 & 1,829 & 1,879 & 97 & 152 \\
\hline 65 & 736 & 792 & 844 & 947 & 1,003 & 108 & 159 \\
\hline
\end{tabular}

rates exceed utility discount rates because of taxation and risk and because increases in productivity over time reduce the marginal utility of consumption. Discount rates as low as 0 percent have been used to discount future utility. ${ }^{30}$ Others have argued for higher discount rates, however. For example, it may be possible to explain why some people smoke if we assume they have individual discount rates of 20 percent or more. ${ }^{31}$ Rather than choose one number, three discount rates are used here, roughly spanning the literature: 0 percent, 3 percent, and 6 percent. Our benchmark assumption is a discount rate of 3 percent.

\section{Health Capital Using the Years-of-Life Approach}

The first five columns of table 1, and figures $4 \mathrm{a}$ and $4 \mathrm{~b}$, show health capital between 1950 and 1990 using benchmark assumptions of a 3 percent discount rate and a $\$ 100,000$ value of a life year. The last two columns of the table show changes between 1950 and 1970, and between 1970 and 1990. The sample is split in 1970 because qualityadjusted health capital after 1970 can only be estimated after 1970 .

Health capital for infants is about $\$ 3$ million; remaining health capital for those age 65 is about $\$ 1$ million. These are large if one thinks of the base as income earned during a lifetime, ${ }^{32}$ although there is no reason why the value of life as a whole cannot exceed an individual's earnings over a lifetime.

30. Ramsey (1927) argued for a social discount rate of zero, citing no ethical reason why future utility ought to be less than current utility.

31. Fuchs (1982).

32. With discounting, the effective number of years of life for an infant is about thirty years. At an income of $\$ 25,000$ a year, this is about $\$ 600,000$. 
Figure 4. Health Capital, 1950-90

A. AT BIRTH

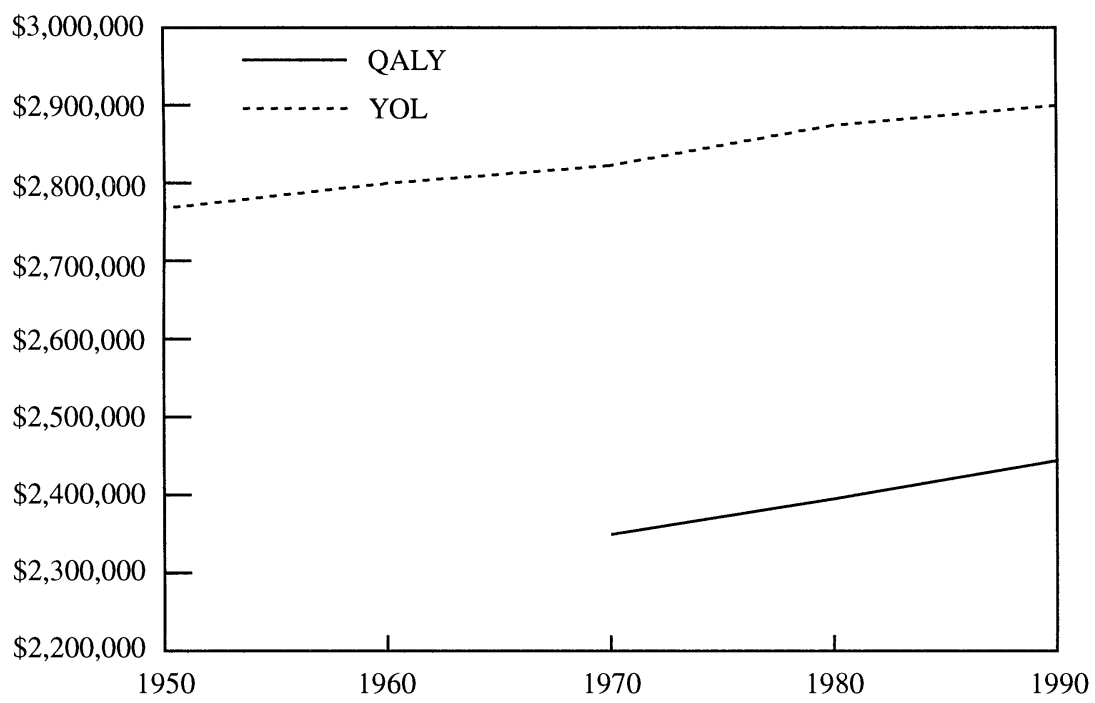

B. AT AGE 65

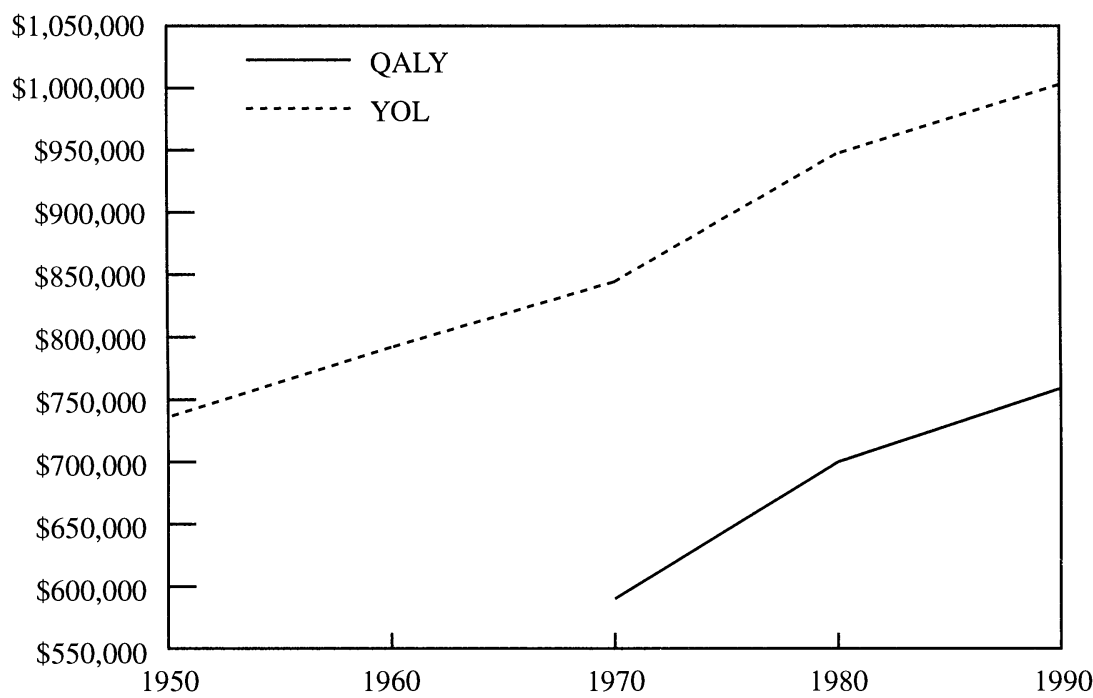


Table 2. Change in Health Capital by Alternative Discount Rates

(thousands of dollars)

\begin{tabular}{rccccccc}
\hline & \multicolumn{3}{c}{$1950-70$} & & \multicolumn{3}{c}{$1970-90$} \\
\cline { 2 - 3 } \cline { 6 - 8 } Age & $r=0$ & $r=.03$ & $r=.06$ & & $r=0$ & $r=.03$ & $r=.06$ \\
\hline 0 & 261 & 55 & 22 & & 408 & 77 & 27 \\
20 & 230 & 66 & 28 & & 385 & 107 & 43 \\
45 & 210 & 97 & 52 & & 329 & 152 & 83 \\
65 & 163 & 108 & 76 & & 240 & 159 & 112 \\
\hline
\end{tabular}

Source: Authors' calculations based on data from Bell, Wade, and Gross (1992).

Note: The change in the dollar value of health capital assumes a value per life year of $\$ 100.000$.

Health capital has increased over time. The change was somewhat more rapid in the 1970-90 period than in the 1950-70 period-about 40 percent more for infants and nearly 50 percent more for the elderly.

Perhaps most important, however, the increase in health capital is greater for the elderly than for infants. For the elderly, health capital increased by nearly $\$ 270,000$ between 1950 and 1990; for infants, the increase was only half as great.

Table 2 shows that this latter result is particularly sensitive to the discount rate chosen. With no discounting, health capital increased more for infants $(\$ 669,000)$ than for the elderly $(\$ 403,000)$. Using a 6 percent discount rate, the increase in health capital for the elderly $(\$ 188,000)$ dwarfs that for infants $(\$ 49,000)$. In all three cases the change in health capital for the elderly is roughly the same; the difference comes in the value of life extension for infants. This sensitivity to discount rates occurs because a large share of the improvement in longevity is a result of declining mortality at older ages. For infants, this occurs sufficiently far in the future that under moderate discounting, it only affects the present value of health by a small amount. For the elderly, the health improvement is more immediate, so the present value is greater.

Table 3 shows this point in detail using the change in health capital resulting from improvements in cardiovascular disease mortality and cancer mortality. Lower cardiovascular disease mortality accounts for a dominant share (about 40 percent) of the improvements in health capital overall. Mortality from cancer, in contrast, actually increased during this time period, although the net effect on health capital was very small. 
Table 3. Contribution of Particular Diseases to Health Capital, Years of Life Approach, 1970-90

\begin{tabular}{|c|c|c|c|c|}
\hline \multirow[b]{2}{*}{ Age } & \multicolumn{2}{|c|}{ Cardiovascular disease } & \multicolumn{2}{|c|}{ Cancer } \\
\hline & $\begin{array}{c}\text { Change in life } \\
\text { expectancy } \\
\text { (years) }\end{array}$ & $\begin{array}{c}\text { Change in } \\
\text { health capital } \\
\text { (thousands of } \\
\text { dollars) }\end{array}$ & $\begin{array}{c}\text { Change in life } \\
\text { expectancy } \\
\text { (years) }\end{array}$ & $\begin{array}{c}\text { Change in } \\
\text { health capital } \\
\text { (thousands of } \\
\text { dollars) }\end{array}$ \\
\hline 0 & 2.7 & 24 & 0.0 & 0 \\
\hline 65 & 2.2 & 95 & -0.2 & -9 \\
\hline
\end{tabular}

Source: Authors' calculations.

Note: Calculations assume a value of a life year of $\$ 100.000$ and a real discount rate of 3 percent.

Are these changes in the value of health capital large or small? One way to gauge the magnitude of these numbers is to look at expected medical care spending over one's remaining life. If all of the increase in longevity was a result of improvements in medical care, it would indicate the benefit-cost ratio for medical care. Clearly, factors other than medical care are important in the improvement in health. But this calculation does give an order of magnitude estimate of how large the improvements in health are.

To form expected medical spending, we use data from periodic surveys of the population conducted in 1970, 1977, and 1987. ${ }^{33}$ Spending is converted to 1990 dollars using the GDP price deflator (using 1990 dollars is akin to assuming the $\$ 100,000$ value of a life year is in 1990 dollars). Average medical spending for people age $a$ in year $t$ is denoted as $m_{t}(\mathrm{a})$. We add up the discounted value of medical spending at each age times the probability that a person is alive at that age to form expected medical spending throughout a person's remaining lifetime: ${ }^{34}$

$$
E_{t}[\text { Medical Spending }(a)]=\sum_{s=0}^{\infty} \operatorname{Pr}\left[\text { Alive }_{t+s}(a)\right] \cdot \frac{m_{t+s}(a+s)}{(1+r)^{s}} .
$$

Table 4 shows the change in expected medical spending over time. For infants, expected medical spending rose from $\$ 59,000$ in 1970 to $\$ 148,000$ in 1987 , for an increase (assuming a 3 percent discount rate) of $\$ 19,000$. For the elderly, the increase was $\$ 34,000$.

The increase in health capital is greater than the increase in medical

33. See Cutler and Meara (1997) for more discussion.

34. The same reservations about whether the cross-section distribution will prevail over time are relevant for this issue as well. 
Table 4. Medical Spending over Lifetime

(thousands of dollars)

\begin{tabular}{rccccccc}
\hline & & & & \multicolumn{3}{c}{ Change, 1970-87 } \\
\cline { 5 - 7 } Age & 1970 & 1977 & 1987 & $r=0$ & $r=.03$ & $r=.06$ \\
\hline 0 & 59 & 77 & 148 & 89 & 19 & 8 \\
65 & 14 & 24 & 62 & 48 & 34 & 27 \\
\hline
\end{tabular}

Source: Authors" calculations based on data from surveys published by the Center for Health Administration Studies, and the National Opinion Research Center (1970). National Center for Health Services Research (1977), and Agency for Health Care Policy and Research (1987). 0 .

Note: Medical spending is in real 1990 dollars. The first three columns show expected spending with discount rate, $r=$

spending for both infants and the elderly. Thus, if all of the increase in health capital resulted from increased medical spending, the medical spending would be worth the money.

In addition to health capital for the population as a whole, we are also interested in health capital for particular subgroups of the population. Table 5 shows the change in health capital by race, sex, and age. Figure 5 summarizes the female-male and black-white "health gaps." Consistent with their longer life, women have more health capital than men; for infants the ratio is about 1.0, and for the elderly it is about 1.4. The trend of female-male health changes over time and is hump shaped. In the 1950s and 1960s women increased their lead over men; life expectancy at birth rose by 3.7 years for women between 1950 and 1970 but only 1.5 years for men. Since 1970, however, men have gained on women. The net effect cancels out the improved health of women in the previous twenty years; the female-male health gap in 1990 is virtually the same as it was in 1950 .

The racial story is very different, however. Between 1950 and 1980, black health improved relative to white health. The health capital of black newborns went from 93 percent of white newborns to 96 percent of white newborns, and that of black elderly went from 63 to 77 percent of white elderly. Since 1980, however, health capital has increased roughly the same amount for the two racial groups, with whites doing slightly better. As table 5 shows, this is really a story of small increases in health for black males. During the 1980s black women had increases in health capital roughly the same as white women; increases in health capital for black males, in contrast, were much smaller than those for white males. 
Table 5. Health Capital By Race and Sex, Years of Life Approach (thousands of dollars)

\begin{tabular}{|c|c|c|c|c|c|}
\hline Age & 1950 & 1960 & 1970 & 1980 & 1990 \\
\hline \multicolumn{6}{|l|}{ Age 0} \\
\hline All & 2,768 & $\begin{array}{r}2,800 \\
{[32]}\end{array}$ & $\begin{array}{r}2,823 \\
{[23]}\end{array}$ & $\begin{array}{r}2,874 \\
{[52]}\end{array}$ & $\begin{array}{r}2,900 \\
{[26]}\end{array}$ \\
\hline \multicolumn{6}{|l|}{ Men } \\
\hline White & 2,737 & $\begin{array}{r}2,769 \\
{[32]}\end{array}$ & $\begin{array}{r}2,784 \\
{[15]}\end{array}$ & $\begin{array}{r}2,829 \\
{[45]}\end{array}$ & $\begin{array}{r}2,872 \\
{[43]}\end{array}$ \\
\hline Black & 2,538 & $\begin{array}{r}2,600 \\
{[62]}\end{array}$ & $\begin{array}{r}2,606 \\
{[6]}\end{array}$ & $\begin{array}{l}2,707 \\
{[101]}\end{array}$ & $\begin{array}{r}2,718 \\
{[11]}\end{array}$ \\
\hline \multicolumn{6}{|l|}{ Women } \\
\hline White & 2,836 & $\begin{array}{r}2,876 \\
{[40]}\end{array}$ & $\begin{array}{r}2,897 \\
{[22]}\end{array}$ & $\begin{array}{r}2,941 \\
{[44]}\end{array}$ & $\begin{array}{r}2,962 \\
{[21]}\end{array}$ \\
\hline Black & 2,622 & $\begin{array}{r}2,701 \\
{[79]}\end{array}$ & $\begin{array}{r}2,758 \\
{[57]}\end{array}$ & $\begin{array}{r}2,846 \\
{[89]}\end{array}$ & $\begin{array}{r}2,865 \\
{[19]}\end{array}$ \\
\hline \multicolumn{6}{|l|}{ Age 65} \\
\hline All & 736 & $\begin{array}{c}792 \\
{[56]}\end{array}$ & $\begin{array}{r}844 \\
{[52]}\end{array}$ & $\begin{array}{r}947 \\
{[103]}\end{array}$ & $\begin{array}{r}1,003 \\
{[56]}\end{array}$ \\
\hline \multicolumn{6}{|l|}{ Men } \\
\hline White & 629 & $\begin{array}{r}660 \\
{[31]}\end{array}$ & $\begin{array}{r}666 \\
{[6]}\end{array}$ & $\begin{array}{r}784 \\
{[118]}\end{array}$ & $\begin{array}{c}868 \\
{[85]}\end{array}$ \\
\hline Black & 409 & $\begin{array}{l}474 \\
{[65]}\end{array}$ & $\begin{array}{c}456 \\
{[-18]}\end{array}$ & $\begin{array}{c}552 \\
{[96]}\end{array}$ & $\begin{array}{l}580 \\
{[28]}\end{array}$ \\
\hline \multicolumn{6}{|l|}{ Women } \\
\hline White & 873 & $\begin{array}{r}965 \\
{[91]}\end{array}$ & $\begin{array}{r}1,020 \\
{[56]}\end{array}$ & $\begin{array}{l}1,135 \\
{[115]}\end{array}$ & $\begin{array}{r}1,179 \\
{[44]}\end{array}$ \\
\hline Black & 536 & $\begin{array}{r}659 \\
{[123]} \\
\end{array}$ & $\begin{array}{r}743 \\
{[84]} \\
\end{array}$ & $\begin{array}{r}903 \\
{[160]} \\
\end{array}$ & $\begin{array}{r}947 \\
{[44]} \\
\end{array}$ \\
\hline
\end{tabular}

Source: Authors' calculations based on data from the Bell, Wade, and Gross (1992).

Note: Calculations assume a value per life year of $\$ 100.000$ and a discount rate of 3 percent. Numbers in brackets indicate change in health capital from the previous decade.

This story of cross-group changes in health parallels some trends in labor markets. Racial changes in health capital are very similar to racial changes in wages. Mean wages for blacks relative to whites, for example, rose relatively steadily from 1950 to 1980 , but then fell slightly over the 1980s. Further, much of this decline in the 1980s resulted from differential changes in wages for black males relative to white males. Speculation about the causality in these two trends has to be deferred to further work.

The changes in health capital by gender are very different from wage 
Figure 5. Health Capital Ratios, 1950-90

A. FEMALE TO MALE

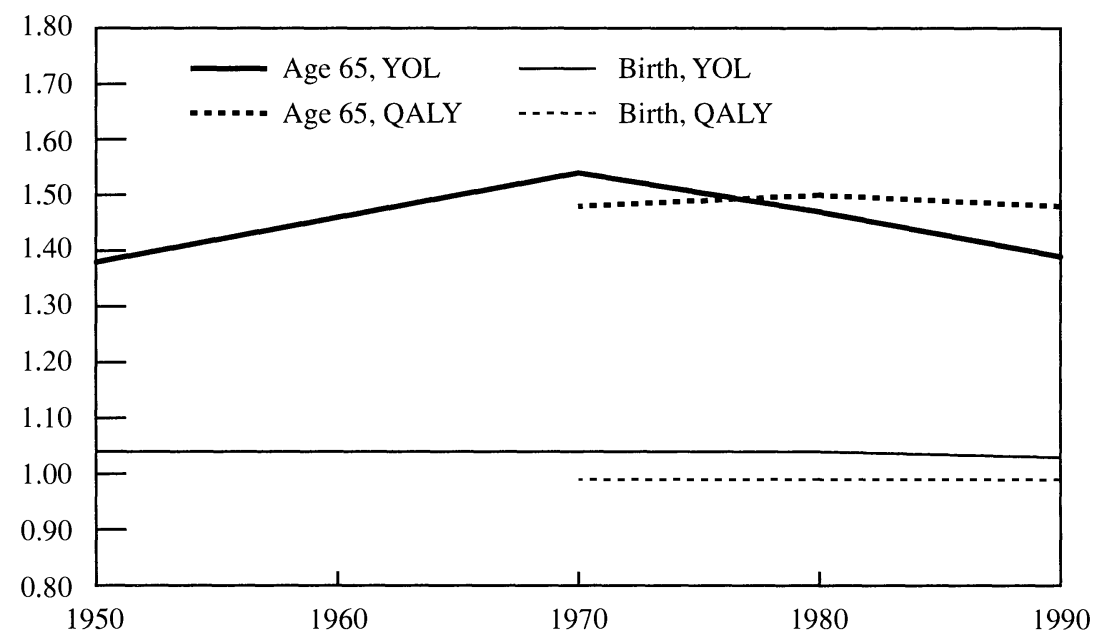

B. BLACK TO WHITE

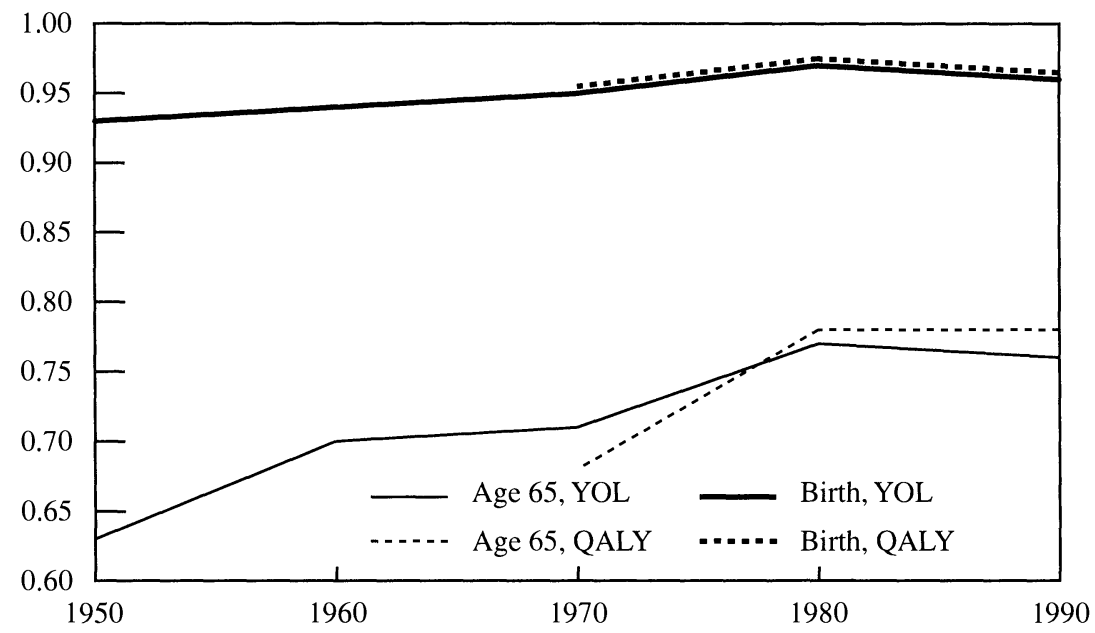

Source: Authors' calculations. Calculations assume a 3 percent discount rate. 
changes by gender. Women's wages were roughly constant as a share of men's wages from 1950 until about 1980, when women's wages increased markedly relative to men (from about 60 percent of men's wages to about 70 percent). The data show that while the wage gap was apparently stuck in the 1950s and 1960s, the health of women was improving relative to men; while the wage gap was falling, the health gap was narrowing.

\section{Incorporating Morbidity}

Having computed mortality-based estimates of health capital, we now incorporate morbidity into our estimates. Valuing morbidity is harder than valuing mortality because the former is so much more difficult to measure. Figure 6 shows a schematic diagram for various types of diseases. Diseases often begin by individuals putting themselves at risk through behavioral or environmental actions. The presence of elevated individual risk, coupled with random events, leads to an onset of illness. Sometimes, the illness results in death; other times, there is complete recovery; and sometimes, the illness becomes a chronic part of life. Chronic illness may be associated with subsequent death, with elevated risk for other diseases, or just with reduced physical or mental functioning.

Figure 6 embeds three types of illnesses that are useful to distinguish. The first type is an acute condition (for example, the flu) characterized by a short period of illness followed by complete recovery. As the illness phase gets shorter, and as mortality from acute illness falls, the salience of acute illness to individuals declines. If asked how healthy they perceive themselves to be, few people today would probably even remember that they had had the flu earlier in the year, although this would not have been true after the great flu epidemic of 1918-19. Moreover, the prevalence of acute illnesses fluctuates wildly from year to year or month to month, making measurement of its underlying trend difficult. As a result, we generally ignore illnesses with very short-term effects when measuring morbidity.

The second type of illness is a chronic condition (for example, arthritis, stroke, or depression). These diseases may be physical (for example, arthritis and stroke) or mental (for example, depression). 
Figure 6. Diseases and Their Morbidity Implications

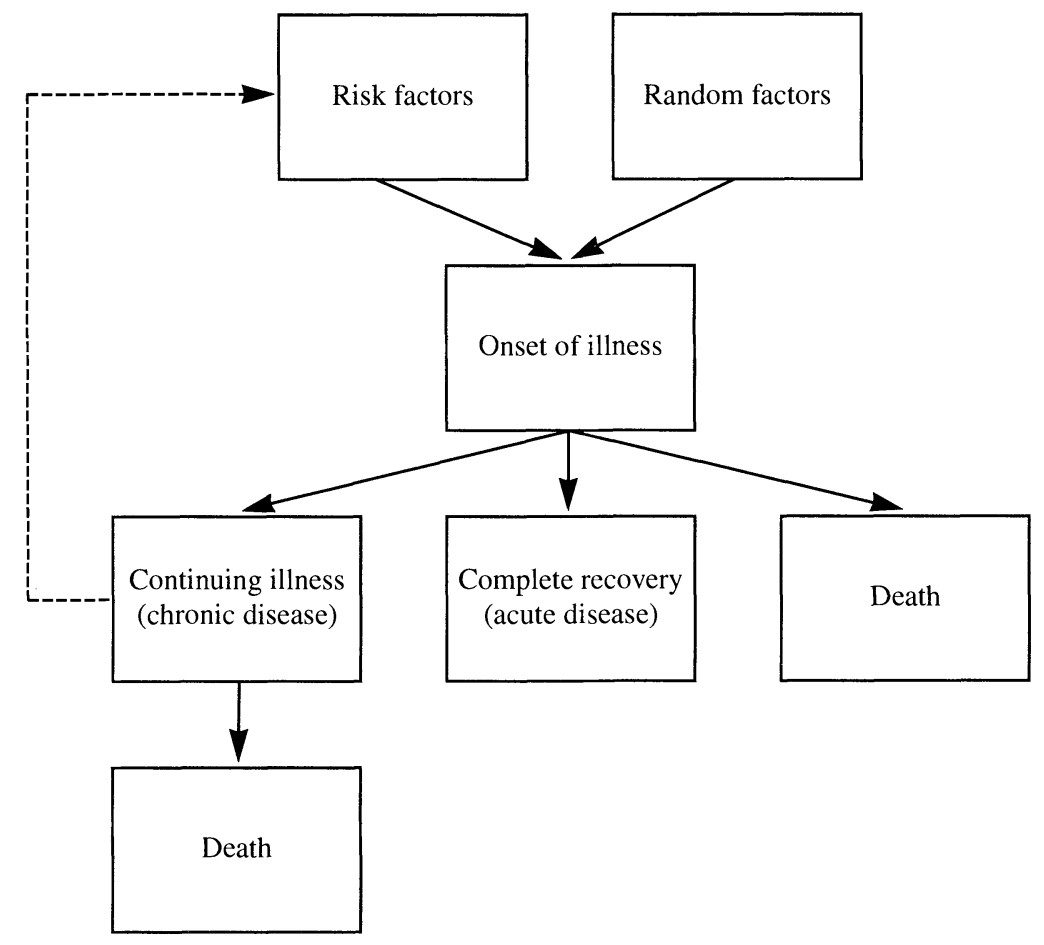

Source: Authors' calculations.

Some chronic diseases (for example, stroke) affect the length of life in addition to its quality, whereas others (for example, arthritis) affect only the quality of life. Some diseases (for example, stroke) place the individual at increased risk of further illness; others (for example, arthritis) do not. Chronic diseases are characterized by a continuous presence that makes them salient to individuals and thus relatively easy to measure.

The third type of illness is a risk factor (for example, hypertension or high cholesterol). Measuring the prevalence of many risk factors is difficult because people with the risk factor who have not experienced an adverse event may be only marginally impaired if they even know they are at risk.

For data reasons, past work on measuring functional status over time 
has frequently limited itself to physical illness only. For example, Fogel and others ${ }^{35}$ and Costa and Steckel ${ }^{36}$ compare long-term changes in physical functioning over the twentieth century, using measures such as the presence of chronic musculoskeletal, circulatory, and respiratory conditions. Manton, Corder, and Stallard look at the prevalence of impairments in activities of daily living (dressing, bathing, and so on) and instrumental activities of daily living (balancing a checkbook, cooking, and so on) in the past twenty years. ${ }^{37}$ But for our purpose, examining physical measures of morbidity alone is incomplete. A methodology is needed that accounts for mental and physical functioning and can incorporate risk factors as well.

Rather than measuring the extent of physical limitations in the population, as previous authors have done, we take a more "structural" approach to morbidity. We begin by identifying major diseases that a person can have and tracing the effect of these diseases on quality of life. We then add up across the range of diseases to get an estimate of overall morbidity.

\section{The Range of Diseases}

The most common source of information on disease prevalence is the annual National Health Interview Survey, which has been conducted since 1957, although micro data are available only from 1969. It is a household-based, personal interview survey consisting of a set of core questions that are relatively constant each year and supplements that change annually. The sample, about 110,000 people annually, is drawn nationwide from the noninstitutionalized, civilian resident population of the United States. The survey is generally believed to be reliable on most acute and chronic illness, but because it is self-report, it is very poor at measuring risk factors. As with all self-reported data, the prevalence estimates can also be sensitive to increased awareness or diagnosis of a disease as well as the phrasing and location of the survey questions.

Tables 6 and 7 show the prevalence of chronic conditions and acute diseases by age in 1990. The major chronic conditions primarily affect

35. Fogel and others (1993).

36. Costa and Steckel (1995).

37. Manton, Corder, and Stallard (1997). 
Table 6. Chronic Condition Prevalence Rate per 1,000 People, 1990

\begin{tabular}{|c|c|c|c|}
\hline \multirow[b]{2}{*}{ Condition } & \multicolumn{3}{|c|}{ Age } \\
\hline & $<18$ & $18-64$ & $65+$ \\
\hline \multicolumn{4}{|l|}{ Endocrine } \\
\hline Diabetes & -- & 45.0 & 186.8 \\
\hline \multicolumn{4}{|l|}{ Circulatory } \\
\hline Heart conditions & 18.9 & 62.8 & 287.3 \\
\hline Arteriosclerosis & -- & -- & 51.0 \\
\hline Stroke & - & 6.3 & 63.0 \\
\hline Hypertension & -- & 105.6 & 369.0 \\
\hline Varicose veins & -- & -- & 74.0 \\
\hline Hemorrhoids & -- & -- & 58.9 \\
\hline \multicolumn{4}{|l|}{ Musculoskeletal } \\
\hline Arthritis & -- & 111.5 & 478.2 \\
\hline \multicolumn{4}{|l|}{ Respiratory } \\
\hline Asthma/bronchitis & 110.9 & 82.7 & 106.8 \\
\hline Hay fever & 56.5 & 108.9 & 67.7 \\
\hline Sinusitis & 56.7 & 159.1 & 151.7 \\
\hline \multicolumn{4}{|l|}{ Digestive } \\
\hline Hernia & -- & -- & 57.0 \\
\hline Constipation & -- & -- & 53.4 \\
\hline \multicolumn{4}{|l|}{ Impairments } \\
\hline Visual & 8.7 & 31.5 & 73.1 \\
\hline Hearing & 21.0 & 81.4 & 321.8 \\
\hline Paralysis & -- & 5.8 & 23.9 \\
\hline Back or extremities & 30.0 & 165.0 & 208.6 \\
\hline
\end{tabular}

Source: Authors calculations from the National Center for Health Statistics (1990).

Note: Dashed lines indicate a prevalence of less than 5 per 1.000 .

the elderly (table 6). Arthritis is the most prevalent chronic disease for people over 65, affecting almost half the people in this age group. Hypertension is the next most common chronic condition among the elderly, followed by hearing impairments and heart conditions. For people ages 18 to 64 , the most common chronic condition is orthopedic impairments, which are present in 17 percent of people this age. Respiratory ailments, including asthma and hay fever, are also relatively common. Chronic conditions are not as common in children under 18 , although more than 10 percent of children suffer from asthma or bronchitis.

Acute conditions, in contrast, are relatively more common in children under 18. In 1990 children had very high rates of influenza, com- 
Table 7. Acute Condition Rate per 100,000 People, 1990

\begin{tabular}{|c|c|c|c|}
\hline & \multicolumn{3}{|c|}{ Age } \\
\hline & $<18$ & $18-64$ & $65+$ \\
\hline \multicolumn{4}{|l|}{ Infective and parasitic diseases } \\
\hline Common childhood diseases & 62.2 & -- & -- \\
\hline Intestinal virus & 108.5 & 32.7 & 14.3 \\
\hline Viral infections & 126.5 & 42.9 & 24.5 \\
\hline Other & 169.8 & 50.3 & 33.1 \\
\hline \multicolumn{4}{|l|}{ Respiratory } \\
\hline Common cold & 421.2 & 195.4 & 153.8 \\
\hline Other acute upper respiratory infections & 194.7 & 57.1 & 39.1 \\
\hline Influenza & 613.5 & 404.9 & 192.5 \\
\hline Acute bronchitis & 66.9 & 32.8 & 36.3 \\
\hline Pneumonia & 20.9 & 11.9 & 23.8 \\
\hline Other respiratory conditions & 35.6 & 12.0 & 26.6 \\
\hline \multicolumn{4}{|l|}{ Digestive system } \\
\hline Indigestion, nausea, vomiting & 45.8 & 21.5 & 21.7 \\
\hline \multicolumn{4}{|l|}{ Injuries } \\
\hline Fractures, dislocations & 36.3 & 25.4 & 18.7 \\
\hline Sprains and strains & 35.9 & 62.4 & 31.4 \\
\hline Open wounds and lacerations & 85.2 & 43.8 & 20.4 \\
\hline Contusions and superficial injuries & 50.0 & 38.1 & 34.1 \\
\hline Other current injuries & 83.1 & 71.7 & 54.3 \\
\hline \multicolumn{4}{|l|}{ Other } \\
\hline Eye conditions & 13.5 & 7.7 & 13.5 \\
\hline Ear conditions & 303.3 & 28.8 & 23.4 \\
\hline Urinary conditions & 11.9 & 26.2 & 50.3 \\
\hline Disorders of menstruation & 7.9 & 5.1 & -- \\
\hline Skin conditions & 32.1 & 11.8 & 24.7 \\
\hline Musculoskeletal conditions & 14.1 & 35.8 & 42.3 \\
\hline Headache & 13.8 & 14.0 & 6.3 \\
\hline Fever & 54.8 & 4.4 & 5.2 \\
\hline
\end{tabular}

Source: Authors' calculations from the National Center for Health Statistics (1990).

Note: Dashed lines indicate a prevalence less than 5 per 1.000 .

mon cold, ear infections, and other infectious diseases. Influenza and the common cold are by far the most prevalent conditions at all ages.

Only diseases for which prevalence over time can be measured accurately are included. After analyzing the National Health Interview Survey documents and comparing disease prevalence from the survey with other data sources, we chose three chronic diseases and six impairments that we believe are comparable over time. The diseases or impairments in the survey believed to be relatively consistently reported 
Table 8. Sources of Chronic Disease Data

\begin{tabular}{|c|c|c|c|c|c|c|}
\hline \multirow[b]{2}{*}{ Disease } & \multicolumn{3}{|c|}{$\begin{array}{l}\text { Age-and sex-adjusted } \\
\text { prevalence per } 1,000\end{array}$} & \multicolumn{3}{|c|}{$Q A L Y$ weight } \\
\hline & 1970 & 1980 & 1990 & 1970 & 1980 & 1990 \\
\hline Amputee & 6.1 & 8.2 & 6.0 & 0.87 & 0.89 & 0.89 \\
\hline Arthritis ${ }^{a}$ & 111.8 & 128.2 & 127.8 & 0.69 & 0.74 & 0.79 \\
\hline Blindness & 8.6 & 6.1 & 2.0 & 0.73 & 0.80 & 0.87 \\
\hline Other vision & 48.0 & 36.0 & 30.2 & 0.84 & 0.88 & 0.93 \\
\hline Cancer & 11.1 & 15.3 & 18.7 & 0.70 & 0.70 & 0.70 \\
\hline Cardiovascular disease & 64.7 & 88.9 & 99.3 & 0.57 & 0.64 & 0.71 \\
\hline Diabetesi $^{\mathrm{a}}$ & 45.9 & 51.3 & 54.3 & 0.65 & 0.65 & 0.66 \\
\hline Hearing & 80.9 & 85.0 & 91.2 & 0.91 & 0.92 & 0.93 \\
\hline Orthopedic & 102.1 & 105.6 & 135.0 & 0.70 & 0.79 & 0.88 \\
\hline Paralysis $^{a}$ & 7.4 & 7.1 & 7.1 & 0.62 & 0.65 & 0.68 \\
\hline
\end{tabular}

Source: Authors' calculations from the National Center for Health Statistics (1969-93) for all diseases except cancer. which are from the National Cancer Institute (1994).

Note: QALY weights are based on calculations described in the text.

a. The QALYs used for these diseases include adjustments for interactions where appropriate. The interaction adjustments for heart disease and diabetes are 0.16, 0.15, and 0.13 in 1970, 1980, and 1990. The interactions for stroke and diabetes are $0.33,0.23$, and 0.14 in 1970, 1980, and 1990. The interactions for arthritis and diabetes are $0.17,0.14$, and 0.11 in 1970. 1980, and 1990. The interactions for stroke and paralysis are $0.24,0.22$, and 0.20 in 1970, 1980, and 1990. The interactions for arthritis and orthopedic impairments are $0.15,0.11$, and 0.07 in 1970, 1980, and 1990 .

since 1970 are amputation, arthritis, cardiovascular disease, diabetes, vision and hearing impairments, orthopedic impairments, and paralysis. No acute conditions are included in the analysis; the morbidity associated with modern acute illnesses and their wide fluctuations by year make it difficult to value these diseases.

In addition to the micro data from 1969 on, we also examined published tabulations from the earlier surveys. A comparison of prevalence rates for the early 1960s and the early 1970s, however, showed dramatic increases in disease prevalence over time that we suspect are more attributable to changes in reporting than to true changes in prevalence. ${ }^{38}$ We thus use only data from 1970 on. Table 8 shows the prevalence of the diseases used in this analysis.

CHRONIC DISEASES. Because the National Health Interview Survey is designed to measure the prevalence of disease in a given year, the actual question varies with the condition. For most cardiovascular conditions, people are asked if they have ever had the condition; for impairments, people are asked whether they have the condition now; and for other

38. For example, the prevalence of cardiovascular disease increased much more in the Health Interview Surveys than in the Framingham Heart Study over the comparable period (Sytkowski and others, 1990). 
Table 9. Chronic Condition Prevalence Rates for the Elderly Population (prevalence per 1,000)

\begin{tabular}{|c|c|c|c|c|c|c|c|c|c|}
\hline \multirow[b]{2}{*}{ Disease } & \multicolumn{3}{|c|}{ Age 65-74 } & \multicolumn{3}{|c|}{ Age $75-84$} & \multicolumn{3}{|c|}{ Over age 85} \\
\hline & 1970 & 1980 & 1990 & 1970 & 1980 & 1990 & 1970 & 1980 & 1990 \\
\hline Amputee & 14.2 & 22.1 & 16.8 & 17.6 & 26.4 & 13.6 & 15.9 & 15.9 & 13.9 \\
\hline Arthritis & 382.2 & 436.7 & 431.5 & 443.2 & 499.8 & 546.0 & 447.2 & 493.3 & 606.6 \\
\hline Blindness & 18.2 & 14.6 & 4.0 & 73.3 & 38.1 & 13.8 & 194.3 & 140.2 & 21.3 \\
\hline Other vision & 116.4 & 78.1 & 54.9 & 277.7 & 116.5 & 83.7 & 259.7 & 169.8 & 124.3 \\
\hline Cancer & 44.9 & 57.5 & 74.4 & 52.4 & 79.2 & 104.0 & $"$ & 89.3 & 106.9 \\
\hline $\begin{array}{l}\text { Cardiovascular } \\
\text { disease }\end{array}$ & 223.0 & 290.7 & 310.1 & 287.1 & 363.9 & 424.2 & 289.0 & 387.1 & 477.5 \\
\hline Diabetes & 4.6 & & 1 & 192.4 & 176.9 & 181.7 & 130.8 & 123.3 & 134.3 \\
\hline Hearing & 216.6 & 234.1 & 255.6 & 374.3 & 343.6 & 362.2 & 516.8 & 469.2 & 507.0 \\
\hline Orthopedic & 169.3 & 170.6 & 191.9 & 217.7 & 172.8 & 210.1 & 229.3 & 203.2 & 261.2 \\
\hline Paralysis & 16.9 & 24.6 & 17.2 & 27.6 & 22.1 & 29.1 & 29.7 & 25.1 & 39.3 \\
\hline
\end{tabular}

Source: Authors' calculations from the National Center for Health Statistics (1969-93) for all diseases except cancer. which are from the National Cancer Institute (1994).

a. Cancer data for 1970 is for $65-74$ and $75+$

diseases, people are asked whether they have had the condition in the past twelve months. ${ }^{39} \mathrm{We}$ define an individual as having the disease if he or she reports having it according to the relevant question.

The first three columns of table 8 show age- and sex-adjusted prevalence rates in 1970, 1980, and 1990 for the diseases we focused on. To compute prevalence, we divide the population by age $(<20,20-$ $44,45-64,65-74,75-84,85+)$ and sex. We then weight the age- and sex-specific prevalence estimates by the population in 1990. Table 9 gives detailed prevalence data for each of the diseases for the elderly population.

As the table shows, the prevalence of cardiovascular disease has been increasing over time. Between 1970 and 1990, cardiovascular disease prevalence rose by 2.2 percent annually for all age groups within the elderly population. Independent evidence on the prevalence of cardiovascular disease can be used to benchmark the National Health Interview Survey. In particular, several longitudinal surveys such as the Framingham Heart Study, the Rochester Heart Study, and the Min-

39. The exact questions follow: "Has anyone in the family ever had ," "'Does anyone in the family now have " and "During the past 12 months, did anyone in the family have __. " If the answer is yes, the question is followed up with "Who was this?" and the questions were then repeated with "anyone else" replacing "anyone in the family." 
nesota Heart Survey have measured cardiovascular illness over time. ${ }^{40}$ Generally, these studies show that mortality from cardiovascular disease has been falling by 2 to 3 percent annually, but the incidence of cardiovascular disease has been declining by only 1 percent annually. Thus the prevalence of cardiovascular disease in the population must be rising at about 1 to 2 percent a year-a rate similar to the estimates obtained from the National Health Interview Survey.

Trends in the prevalence of other diseases over time are mixed. Arthritis, orthopedic impairments, hearing problems, and diabetes have been rising over time; blindness and other visual impairments have been falling. This general increasing trend may in part result from the concurrent gains in life expectancy. If people who would have died twenty years ago are now alive but are sicker on average than the rest of the population, the prevalence of diseases such as arthritis would be expected to rise at a given age. In addition, the increased prevalence of risk factors for some of these diseases may play a role. For example, the increase in diabetes may result from the increasing prevalence of obesity. Of course, there may also be possible changes in reporting or measurement practices over time, but these cannot be separated out.

Two chronic conditions we would like to include but the National Health Interview Survey does not ask about reliably are cancer and mental illness. To measure cancer prevalence, we use data from the National Cancer Institute's Surveillance, Epidemiology, and End Results (SEER) Program. SEER collects detailed cancer incidence and mortality data on a continuing basis at nine registry sites covering approximately 9.5 percent of the U.S. population (Connecticut, Iowa, New Mexico, Utah, Hawaii, Detroit SMSA, Atlanta SMSA, San Francisco-Oakland SMSA, and Seattle-Puget Sound). Prevalence for cancer is more difficult to define than prevalence for arthritis or cardiovascular disease. Some effects of cancer may linger throughout a person's life, but most of the morbidity consequences of cancer are in the heavy treatment phase-generally the first five years with the disease. We thus model cancer as affecting health only during the first five years after onset.

40. Burke and others (1989), Demirovic and others (1993), Doliszny and others (1994), Gomez-Marin and others (1987), Higgins and Thom (1993), Ho and others (1993), Hunink and others (1997), McGovern and others (1992, 1993, 1996), Pell and Fayerweather (1985), Sytkowski and others (1990, 1996). 
The SEER database does not give cancer prevalence, but rather its incidence and annual survival rate (by year after diagnosis). We use these data to compute prevalence over time. We find that cancer prevalence has increased quite a bit over time, by 2.8 percent a year (see table 8 ). Some of this increase may be spurious; in the late 1970s, early detection rates for cancer increased markedly as mammography and CT scans came into greater use. ${ }^{41}$ This increased testing boosted the rate of cancer incidence. Furthermore, because early detection cases tend to survive longer, five-year survival improved. The net effect is a large increase in prevalence. Almost certainly, some of this measured prevalence increase is not real. Because cancer is so important to quality of life, however, these unadjusted data are left in our estimates.

The second disease category the National Health Interview Survey does not measure reliably is mental illness. Mental disorders are quite common; the lifetime prevalence for depression in the United States is estimated to be around 17 percent. ${ }^{42}$ Unfortunately, most studies of mental illness in the United States have focused on small geographic areas and the questions are not comparable over time. Data from the Epidemiologic Catchment Area Study (ECA), which assessed mental illness in five U.S. sites between 1980 and 1983, indicate tremendous variation in the prevalence of mental illness across cities. ${ }^{43}$ The other large national study of mental disorders, the National Comorbidity Survey, fielded in 1990-92, yielded prevalence numbers substantially different from those in the ECA. ${ }^{44}$ Because of these inconsistent estimates, we do not incorporate any mental disorders into our health capital measure. This is a major issue for future analysis, particularly given the recent and large advances in treatments for mental illness. ${ }^{45}$

RISK FACTORS. We would also like to include risk factors such as body mass index, cholesterol, hypertension, and smoking in our measure of health. Most of these risk factors are associated with cardiovascular disease, ${ }^{46}$ but they also increase the risk of cancer, diabetes, and other illnesses.

41. Ernster and others (1996).

42. Blazer and others (1994).

43. Robins and others (1984), Somervell and others (1989), Wickramaratne and others (1989).

44. Blazer and others (1994).

45. Frank and Berndt (1997).

46. Larson (1995), Schauffler and others (1993). 
Risk factor changes over time have been quite large. For example, data from the Framingham Study indicate that the percentage of men with definite hypertension declined from 21 percent to 15 percent between the 1950 and 1970 cohorts. This is a direct result of the spread of more effective antihypertensive medications. ${ }^{47}$ Indeed, reduced presence of risk factors is generally believed to be the single largest factor in reduced cardiovascular illness over time. ${ }^{48}$

Incorporating risk factors is not straightforward, however. Some risk factor changes are already included naturally. Those that are common to older and younger people will be accounted for in the cross-section prevalence rates used to measure health. Risk factor changes not common to the two groups are not incorporated using cross-section prevalence rates, however. If a 45-year-old today is more likely to have her hypertension controlled than a 65-year-old was twenty years ago, for example, and early hypertension control has long-term health benefits, that 45 -year-old will be less likely than a current 65 -year-old to suffer from cardiovascular disease when she is 65 . This will not be measured in looking at the cross-section prevalence profile.

To address this issue, we would need to measure risk factor changes over time and then know the relation between these risk factors and subsequent disease. Although evidence exists on both of these, our ability to conduct this analysis is limited. Risk factor data are generally measured cross-sectionally, not longitudinally. Further, finding the correct model relating long-term risk factor changes to disease is also problematic. We therefore do not attempt an adjustment for risk factors in this paper, but instead rely on the cross-section prevalence data to capture some risk factor changes. As a result, our estimates of improvements in health capital over time are probably conservative. Incorporating risk factor changes into measurement of health capital is an important subject for future research.

\section{Assigning QALY Weights to Illness}

Knowing the prevalence of disease is not enough to measure morbidity. We also need to know the QALY weight for the disease. These weights can be measured in three ways. First, surveys can be conducted

47. Sytkowski and others (1990).

48. Hunink and others (1997). 
to learn how bad a particular health state is. For example, to form a QALY weight for paralysis, people can be asked to judge quality of life with and without paralysis. The literature on exactly how this question ought to be asked is quite lengthy. ${ }^{49}$ Generally, the consensus is that one should ask questions using standard gamble or time trade-off methods, which have a theoretical grounding in von Neumann-Morgenstern utility theory. ${ }^{50}$ The standard gamble usually gives a choice between some health state with certainty and a gamble involving instant death or perfect health, and measures the probability of death that makes the respondent indifferent between the alternatives. The time trade-off method presents a certain number of years in a given health state and asks how many years of healthy life would make the individual indifferent between the two options. Alternative methods include rating scales and visual analogue methods. In practice, there is no accepted " "set' of QALY weights developed from this or any other method. In fact, a recent review of QALY methodology found that only 22 percent of cost-effectiveness analyses published between 1975 and 1995 used time trade-offs or standard gambles to assign QALY weights; nearly 40 percent used " author's judgement.,",51

An obvious difficulty with the survey approach is the speculative nature of the question. People who are not paralyzed are likely to have little sense about what life with paralysis would be like. Assigning a QALY weight to a condition one has never had is necessarily perilous. Indeed, in the QALY literature, it turns out that people in a poor health state generally rate their health higher than people not in that health state think their health would be if they had that condition. ${ }^{52}$ This type of paradox reflects the difficulty in answering such hypothetical questions.

The second method of measuring QALY weights is related to the first: to survey medical experts about quality of life associated with different functional limitations. Medical experts presumably have more information about what living with particular functional limitations involves than do laypeople without medical training. This approach, taken

49. See, for example, Torrance (1986) for a review of methods.

50. Gold and others (1996).

51. Neumann, Zinner, and Wright (1997).

52. See, for example, Epstein and others (1989), Najman and Levine (1981), and Sackett and Torrance (1978). 
in a recent study for the World Bank and the World Health Organization, The Global Burden of Disease,$^{53}$ seems unsatisfactory, however, without some evidence on how the opinions of medical experts differ from nonmedical experts more generally.

A further difficulty with these two survey methods is crucial in our context: QALY questions are typically asked only once, and we are particularly interested in how quality of life for a given disease has changed over time. For example, it is almost certainly the case that quality-adjusted life for people who are paralyzed has improved: new technologies make living with paralysis easier; social changes such as wheelchair ramps have improved mobility; and even the stigma associated with paralysis has decreased over time. Because the prevalence of many diseases is high, changes in the QALY weights over time can have a substantial effect on measurements of health.

We instead follow a third approach to measuring QALY weightscomparing self-reported health for people with and without particular functional limitations. The estimate of how much worse health people with a particular limitation report they are in relative to people without that limitation is an estimate of the QALY weight for that limitation. By conducting this evaluation in different years, we can see how QALY weights change over time.

Conceptually, our approach is similar to a survey asked of people with and without paralysis. Rather than ask each person how bad paralysis is, we ask people how satisfied they are with their health in general. We then attribute the difference in average satisfaction between people with and without paralysis to the effect of paralysis. Clearly, any other factors differential to people with paralysis will be embedded in these estimates, but if enough controls are included or if these factors do not change over time, we will have an unbiased estimate of the effect of paralysis and its associated physical and mental implications. This method is preferable to the others in the literature because it is straightforward for people to answer, it is based on individual, not expert, opinion, and it has been conducted over time so we can see how QALY weights vary. ${ }^{54}$

\section{Murray and Lopez (1996).}

54. A related approach was taken by Fryback and others (1993) whose survey asked people how healthy they were and related that response to the number of conditions the people reported. They found that people reporting more chronic conditions had lower 
Operationally, we use data in the National Health Interview Survey on self-reported health status. In particular, the survey asks people, "How would you rate your health as compared with other individuals your age?', We order these responses from 5 (excellent) to 1 (poor). Previous research has shown that people who report themselves in poor health are more likely to die than people who report themselves in excellent health. ${ }^{55}$

To use this information, we assume that people have a latent measure of health, $h^{*}$, which is related to diseases $(d)$, demographic characteristics such as age and sex $(X)$, and a random error term:

$$
h^{*}=d \beta+X \gamma+\epsilon .
$$

Equation 9 includes both the diseases we wish to measure QALY weights for, as well as the other diseases not believed to be comparable over time. We include these other diseases to avoid spurious correlation between the conditions we are interested in and the other conditions.

Assuming $\epsilon$ is distributed normally, we can estimate equation 9 using an ordered probit model. In addition to the $\beta$ and $\gamma$ coefficients, the model also gives a set of coefficients $c_{1}$ through $c_{4}$, the break points between excellent and very good health, very good health and good health, and so on.

The $\beta$ s that the model estimates are not scaled in any particular fashion. Indeed, they can range from $\infty$ to $-\infty$ because that is the range of $h^{*}$. We clearly need a normalization to produce a QALY weight. To normalize the coefficients, we divide them by the difference between the borderline of excellent health and that of poor health. Note that $c_{1}$ is the value of $h^{*}$ at which the person will begin to report excellent health and $c_{4}$ is the value at which he or she will report poor health. Assuming these correspond to near perfect health and near death, we can estimate the QALY weight for disease $i$ as $Q A L Y_{i}=\beta_{i} /\left(c_{1}-\right.$ $\left.c_{4}\right) .{ }^{56}$

self-assessed well-being on a number of scales. Each additional condition led to about 3 percent lower well-being.

55. See Idler and Kasl (1995) for a review.

56. Making this normalization is imposing an additional assumption: A movement of 1 anywhere in the distribution (for example, from 1 to 2 , or from 3 to 4 ) represents the same change in underlying health. This is not obviously true because the responses are more qualitative than quantitative. Still, we cannot avoid some assumption of this form. For example, even if we used the estimates to find the share of people with 
In addition to estimating the QALY weight for particular diseases, we also implicitly have QALY weights for people of different ages and sexes. That is, if people compare themselves to the average person in the population, the $\gamma$ 's associated with age will tell us how health varies by age and sex. ${ }^{57}$ We estimate age factors by including age and age ${ }^{2}$ into the regression, and we interact each of these with the dummy variable for men. ${ }^{58}$

An important issue in the estimation of equation 9 is interactions among the set of diseases and between the diseases and demographic variables. Assuming linearity among the set of diseases is problematic. Having heart disease and diabetes is almost certainly not as bad as the effect one would predict from having diabetes and heart disease separately because many of the implications for quality of life will be the same.

This concern is particularly important for a disease such as diabetes that is a risk factor for other diseases. For example, one complication is retinopathy, which can lead to poor vision or blindness. Diabetes is also a risk factor for cardiovascular disease, kidney disease, and neuropathy. Indeed, cardiovascular disease is the leading cause of death for diabetics. Finally, diabetes often results in vascular disease, including lower extremity arterial disease and other diseases that can lead to amputation.

To address the linearity issue, we examined the most prevalent combinations of diseases in the population. Five combinations showed a particularly high joint prevalence: diabetes and stroke, diabetes and heart disease, diabetes and arthritis, stroke and paralysis, and arthritis and orthopedic impairments. We include interaction terms for these five combinations.

One might also want to interact diseases with the demographic variables. Diseases that limit a person's ability to engage in strenuous

different conditions in different levels of health (excellent, very good, and so on), we would still need to assign QALY weights to the different responses.

57. Although questions about self-reported health status typically ask people to compare themselves to others of their own age, it is not clear how individuals answer this question. As we discuss later, there is some evidence of age-norming in the responses and some evidence of population-norming.

58. If we include additional age interaction terms, the regressions tend to overfit age-for example, making many changes in the quality of life for the elderly-that are likely due to small numbers of observations. 
physical activity, for example, may affect the quality of life of the young more than the elderly. Because the sample sizes for some of the disease-demographic interactions are small, however, such interactions are not included.

Table 10 shows estimates of the ordered probit model. The latter three columns use data from the 1989-91 Health Interview Surveys. The estimates of $\beta$ are quite reasonable. All main effects are negative, and the cross effects are positive, as we would expect. Further, the relative magnitudes seem sensible. Conditions generally considered serious, such as stroke, heart disease, and paralysis, have relatively low coefficients; less serious conditions such as poor vision and sinus problems have relatively high coefficients.

The last column of table 10 shows the implied QALY weights. Comparing these with existing QALY results is difficult because no standard set of estimates exists in the literature. The estimated implied QALY weight for heart disease $(0.71)$, however, falls within the range of QALY weights estimated for various types of heart disease in published studies $(0.5-1.0) .{ }^{59}$ Figure 7 shows the implied age factors for men and women. Recall that the higher incidence of disease at older ages is already accounted for with the disease indicator variables. A fairly pronounced decline in quality-adjusted life occurs as people age. Relative to newborns, 20-year-olds have 94 percent as high a quality of life, 65-year-olds have 73 percent as high a quality of life, and 85-yearolds have 62 percent as high a quality of life.

To examine how the QALY weights have changed over time, we estimated a similar model using data from 1979 to 1981 . In these years, the self-reported health question included only four responses (very good was omitted), but this does not affect our empirical methodology. ${ }^{60}$

The results of this estimation are reported in the first columns of table 10. The relative magnitude of the coefficients is similar across years. The correlation between the QALY weights in 1979-81 and 1989-91 is 0.99, for example.

59. Neumann, Zinner, and Wright (1997).

60. We tested the importance of this change by grouping the 1990 data into the category of the 1980 data (combining the "very good" and "good" responses). The QALY estimates from the augmented 1990 model were virtually identical to the QALY estimates in table 10 . 


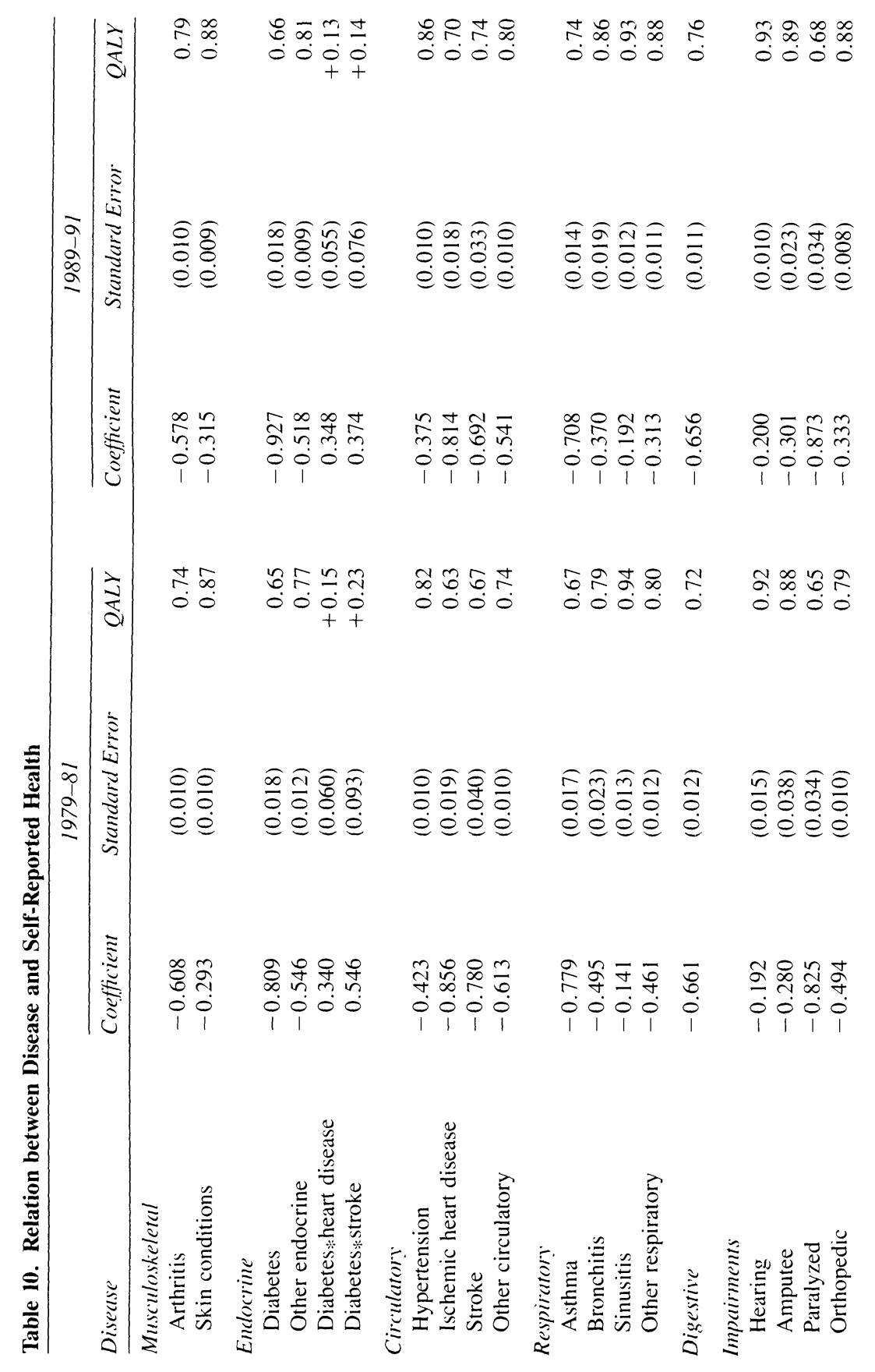




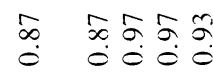

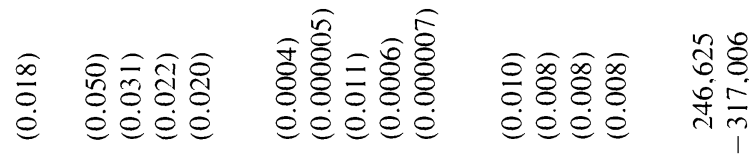

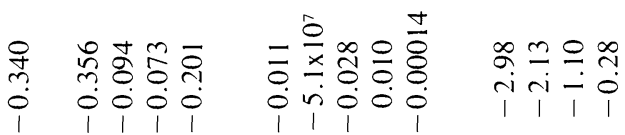

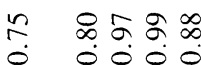

용
0.8
0.0

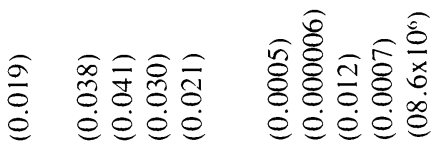

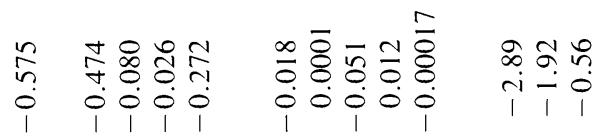

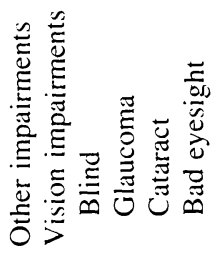
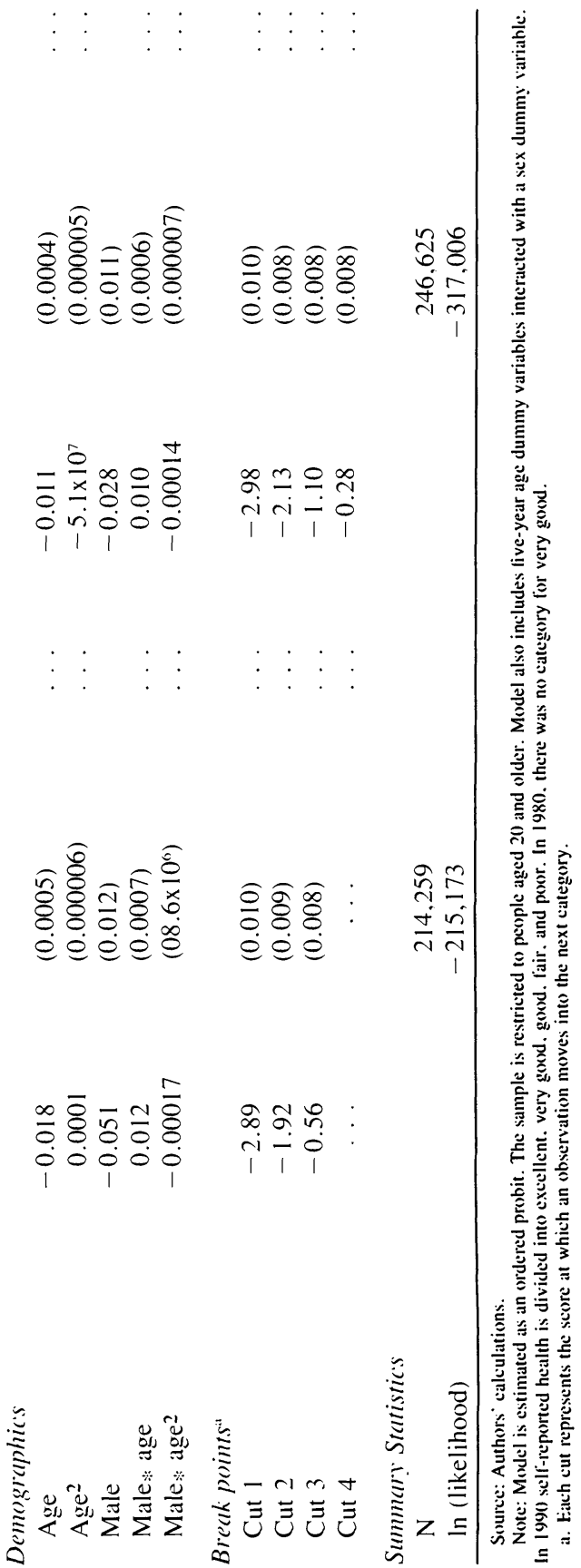
Figure 7. Implied Quality-of-Life Age Factors

QALYS

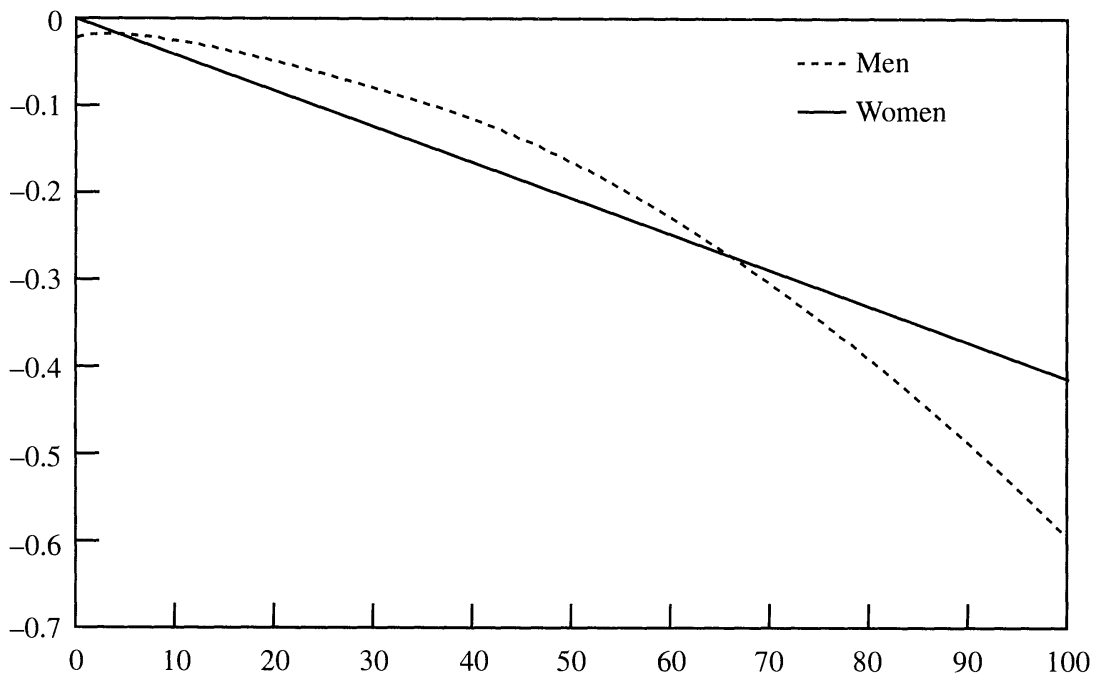

Source: Authors' calculations from National Center for Health Statistics (1990).

But although the relative QALY scales are the same, in absolute terms the disutility associated with nearly every disease has declined over time. For example, the QALY for heart disease rises 10 percent from 1980 to 1990 (from 0.63 to 0.70), and the QALY for orthopedic impairments increases 13 percent (from 0.79 to 0.88 ). For the average disease, the QALY weight increased by about 5 to 10 percent between 1980 and 1990. On the basis of these survey questions, people clearly seem to think that having a disease is associated with less health reduction than it was in the past. This finding matches well with information on disability presented in Manton, Corder, and Stallard. ${ }^{61}$ They estimated that the prevalence of limitations among the elderly on activities of daily living and instrumental activities of daily living was falling by more than 1 percent a year between 1982 and 1994. Our estimates of health improvements are somewhat smaller but qualitatively similar.

Our estimates of the age coefficients were not as consistent, however. For women the estimates suggested a pronounced increase in quality-

61. Manton, Corder, and Stallard (1997). 
adjusted life at very old ages in the 1980 data that was not present in the 1990 data. The problem appeared to be one of age-norming in the responses. Although we would like people to report on their selfreported health relative to the population average, people may report on their health relative to prior expectations of their health at that age or to the health of other people their age. This would bias the age coefficients toward zero and could explain why self-reported health increases at very advanced ages. ${ }^{62}$ Because we suspect this pattern results from age-based changes in the reference point for the question, rather than true changes in health at older ages, we do not use 1980 age estimates in our analysis. We assume instead that the age factors from 1990 prevail throughout the time period.

Unfortunately, the National Health Interview Survey does not ask about self-reported health before 1978, so we cannot extend our estimates further back in time. We need to make some assumption about pre-1980 QALY weights, however, so we can estimate health capital. We assume that the trend in QALY weights we observe from 1980 to 1990 was the continuation of a trend from 1970 to 1980 . We then forecast back to 1970 using these results (see table 8).

Our methodology cannot be used for diseases not reported in the National Health Interview Survey, such as cancer. No conclusive surveys have assigned a QALY weight for the disease. The range of QALY weights used in the literature for various types and stages of cancer is 0.3 to $0.9 .{ }^{63}$ In the treatment phase of cancer, the QALY weight is assumed to be 0.7 . We keep this value constant over time.

\section{Measuring Health Capital II: The Quality-of-Life Approach}

After incorporating all of the diseases and the age effects discussed in the previous section, figure 8 shows the average QALY weight by age in 1970 and 1990. The graph shows the average QALY for those who are alive; zeros have not been factored in for people who are dead.

On net, health has improved over time, particularly at older ages.

62. There is a somewhat prophetic story about a frail elderly woman in a nursing home who was asked her self-reported health and responded, "excellent." When asked how this could be the case, she responded, "Well, everyone else my age is dead!"

63. Neumann, Zinner, and Wright (1997). 
Figure 8. Expected QALYs by Age

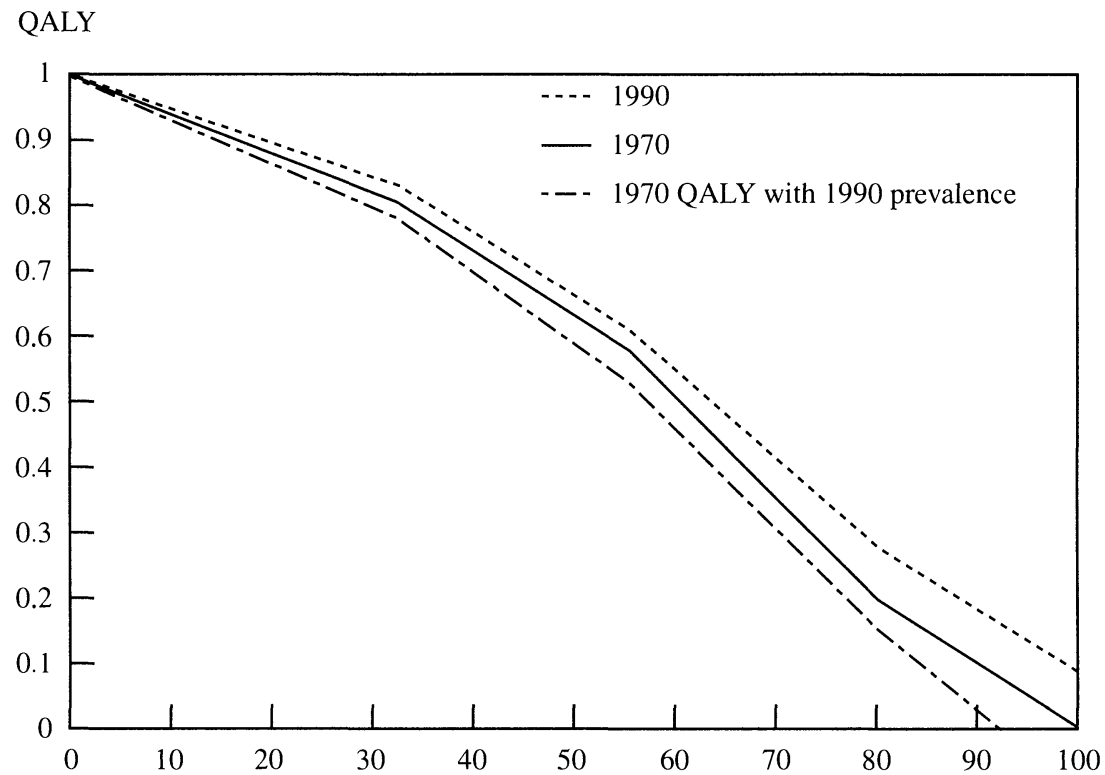

Source: Authors' calculations.

For people at age 65, for example, quality-adjusted health improved by about 0.1 between 1970 and 1990 . The net improvement in health masks two underlying trends, however. First, the prevalence of disease among the population is rising. This is particularly true for the elderly and results in large part from the dramatic reduction in death from cardiovascular disease. Fewer deaths from cardiovascular disease means more people surviving with cardiovascular illness and more people at risk for other chronic conditions. The effect of increased disease prevalence is shown as the lower line in figure 8 . At older ages, increased disease prevalence by itself reduces quality-adjusted life by as much as 30 percent.

But health conditional on disease has improved. This is the implication of our finding that quality of life conditional on disease has risen. This latter effect is sufficiently large that the average person in 1990 is healthier than the average person in 1970 , even with more people having a chronic condition.

To form quality-adjusted health capital, we weight these age-specific 
Table 11. Summary Measures of Health Capital

(thousands of dollars)

\begin{tabular}{|c|c|c|c|c|c|c|}
\hline \multirow[b]{2}{*}{ Measure } & \multirow[b]{2}{*}{1970} & \multirow[b]{2}{*}{1980} & \multirow[b]{2}{*}{1990} & \multicolumn{3}{|c|}{ Change } \\
\hline & & & & $r=0$ & $r=.03$ & $r=.06$ \\
\hline \multicolumn{7}{|l|}{ Age 0} \\
\hline YOL & 2,823 & 2,874 & 2,900 & 408 & 77 & 27 \\
\hline QALY & 2,350 & 2,395 & 2,444 & 387 & 95 & 38 \\
\hline \multicolumn{7}{|l|}{ Age 65} \\
\hline YOL & 844 & 947 & 1,003 & 240 & 159 & 112 \\
\hline QALY & 590 & 700 & 759 & 247 & 169 & 122 \\
\hline \multicolumn{7}{|c|}{ Effect of Specific Factors } \\
\hline \multicolumn{7}{|c|}{ Cardiovascular Disease } \\
\hline Age 0 & $\ldots$ & . . & $\ldots$ & . & 5 & $\ldots$ \\
\hline Age 65 & $\ldots$ & . . & . . & . . & 37 & $\ldots$ \\
\hline \multicolumn{7}{|l|}{ Cancer } \\
\hline Age 0 & $\ldots$ & . . & . . & $\ldots$ & 2 & $\ldots$ \\
\hline Age 65 & $\ldots$ & $\ldots$ & $\ldots$ & $\ldots$ & -14 & $\ldots$ \\
\hline
\end{tabular}

Source: Authors' calculations.

Note: Effect of cardiovascular disease and cancer include changes in mortality, disease prevalence, and QALYs.

QALY weights by the share of people alive at each age. The formula is the same as for the years-of-life approach, except that instead of the survival probability we use the expected quality of life in each year:

(10) Health Capital, (a)

$$
=\left(\frac{U_{H}}{U_{c}}\right) \cdot\left[\frac{\text { Alive }_{t}(a)}{\operatorname{Born}(t-a)}\right] \cdot\left[\sum_{s=0}^{\infty} \frac{E\left(Q A L Y_{t+s}\right)}{(1+r)^{s}} \mid \text { Alive }_{t}\right] .
$$

Table 11 and figure 4 show health capital using the quality-adjusted life year method. For infants, QALY-adjusted health capital (using a 3 percent discount rate) rose by $\$ 95,000$ between 1970 and 1990. For the elderly, the increase in QALY-adjusted health capital was $\$ 169,000$. Both of these numbers are greater than the increase in expected medical spending over the course of the remaining life.

The bottom panel of table 11 shows the contribution of specific diseases to the change in health capital. Cardiovascular disease accounted for about one-fifth of the increase in discounted health capital. Cancer again has a small negative impact on health capital.

Comparing the two measures of health capital by age shows that the 
Table 12. Change in QALY Health Capital by Race and Sex

(thousands of dollars)

\begin{tabular}{lrrrrrrr}
\hline & \multicolumn{3}{c}{ Age 0 } & & \multicolumn{3}{c}{ Age 65 } \\
\cline { 2 - 3 } \cline { 7 - 8 } Group & 1970 & 1980 & 1990 & & 1970 & 1980 & 1990 \\
\hline Men & & & & & & \\
White & 2,364 & 2,404 & 2,471 & & 483 & 570 & 627 \\
& & {$[41]$} & {$[67]$} & & {$[87]$} & {$[58]$} \\
Black & 2,255 & 2,348 & 2,377 & & 311 & 394 & 427 \\
& & {$[93]$} & {$[29]$} & & {$[83]$} & {$[32]$} \\
Women & & & & & & \\
White & 2,348 & 2,387 & 2,437 & & 716 & 843 & 910 \\
& & {$[39]$} & {$[50]$} & & {$[128]$} & {$[66]$} \\
Black & 2,226 & 2,305 & 2,361 & 501 & 689 & 747 \\
& & {$[79]$} & {$[56]$} & & {$[188]$} & {$[58]$} \\
\hline
\end{tabular}

Source: Authors" calculations.

Note: Calculations assume a real discount rate of 3 percent. Numbers in brackets indicate change from previous decade.

difference between the YOL and QALY measures is important. QALY measures of health capital are below YOL measures of health capital but typically rise more rapidly. With our benchmark assumptions, the additional increase in health capital under the QALY approach is as high as 30 percent. We get a misleadingly small measure of improvements in health looking at years of life alone.

Again, discounting has a very big effect on the relative changes in health capital for people of different ages. When we do not discount, we find that health has improved most for infants and that the improvement declines with advancing age. Using a 3 percent discount rate, however, we find that health improves most for the elderly and the least for children. These findings are similar to those using the YOL approach and indicate that most of the health improvement during this period has come at advanced ages.

Our conclusions about gender and racial changes in health capital, shown in table 12 and figure 4, are somewhat different using the QALY measure rather than the YOL measure. Between 1970 and 1990 the rate of female to male health was relatively constant. At birth women and men have nearly identical health capital, and at age 65 women have more health capital. This pattern is relatively constant over time. The prevalence of chronic disease appears to have increased faster for men 
Table 13. Sensitivity Analysis for Health Capital

(thousands of dollars)

\begin{tabular}{|c|c|c|}
\hline \multirow[b]{2}{*}{ Assumption } & \multicolumn{2}{|c|}{$\begin{array}{l}\text { Change in health capital } \\
\qquad 1970-1990\end{array}$} \\
\hline & 0 & 65 \\
\hline Benchmark & 95 & 169 \\
\hline No QALY change & 18 & 91 \\
\hline Double QALY change & 183 & 258 \\
\hline Greater prevalence increase & 60 & 145 \\
\hline Smaller prevalence increase & 134 & 215 \\
\hline Low-gain scenario & -13 & 62 \\
\hline High-gain scenario & 212 & 284 \\
\hline
\end{tabular}

Source: Authors' calculations.

Note: Calculations assume a 3 percent discount rate. The low-gain scenario assumes no QALY change and a greater prevalence increase. The high-gain scenario assumes twice the QALY change and a smaller prevalence increase.

than women over this time period, offsetting some of the relative gain in life expectancy for men.

The black to white health capital ratio is similar using the QALY measure and the YOL measure. Between 1970 and 1980 blacks gained relative to whites, but they lost some of that increase in the 1980s. Again, the reversal of the black to white health capital gap is largely a function of differential changes for black and white males.

\section{Sensitivity Analysis}

Clearly, our estimates are subject to substantial uncertainty. In addition to the question of the appropriate discount rate, discussed earlier, three sources of uncertainty are particularly important. The first is the value of a year of perfect health. The effect of changing the value of a life year is multiplicative; if we assume a $\$ 50,000$ value for a life year, we would just multiply all of the QALY measures by one-half. Naturally, this effect can be quite large.

The second type of uncertainty is how QALY weights have changed over time. To illustrate the importance of this assumption, table 13 shows simulations of changes in health capital for different changes in QALYs. ${ }^{64}$ The second row of the table shows the change in health

64. Because we have multiple sources of uncertainty in our analysis, we do not 
capital assuming QALYs were unchanged between 1970 and 1990 (using the 1990 values). In this scenario, virtually no improvement in health capital for infants and only half the improvement in health capital for the elderly is observed. Conversely, if the assumed change in QALYs during this time period is doubled, as shown in the third row of the table, the improvement in health capital for infants is doubled, and the improvement in health capital for the elderly is increased by nearly 50 percent. These effects are large.

The third source of uncertainty is the change in disease prevalence. The reported prevalence of disease will change both because of true changes in population health and because disease prevalence likely responds to changes in treatment options over time. The next two rows of table 13 examine the sensitivity of our results to changes in disease prevalence. We simulate a greater increase in disease prevalence by assuming that the true disease prevalence in 1970 was two standard deviations below the estimated level in that year and that the true disease prevalence in 1990 was two standard deviations above the estimated level in that year. We reverse these two assumptions for a smaller increase in disease prevalence. Changes in disease prevalence have a smaller effect on changes in health capital than do changes in the QALY weights. Changes in disease prevalence affect changes in health capital for infants by about 40 percent; for the elderly, the effect is about 15 percent.

The final rows of the table show lower and upper bounds for changes in health capital, combining the assumptions in the previous four rows. Our lower-bound estimate is that health capital was unchanged for infants and rose about $\$ 60,000$ for the elderly. Our upper-bound estimate is an improvement in health capital of about $\$ 200,000$ for infants and about $\$ 300,000$ for the elderly.

Producing more refined QALY estimates is the part of our calculation that seems most amenable to further research. As noted earlier, substantial research has been conducted on the value of a life year. Although no consensus has been reached on a particular number, the range of estimates is relatively tight. There is much less agreement, however, on appropriate QALY weights. The methodology in this paper, and in 
other recent work noted here, suggests that estimates of these values could improve substantially in the future.

\section{Conclusions}

People are healthier than they used to be. The dollar value of the health improvement between 1970 and 1990 was about $\$ 100,000$ to $\$ 200,000$. This improvement is the net result of three factors: an increase in the length of the typical life, a greater prevalence of disease during that life, and an improvement in the mental and physical aspects of health conditional on disease.

At one level, it is not surprising that people are estimated to be healthier than they were in the past. Many social indicators-infant mortality, debilitating disease, and so on-have all improved. But our results do show some interesting trends that would not otherwise be apparent. The rate of discounting has a large effect on which age group is perceived to be best off over time. With no discounting, infants have the largest improvement in health capital, and the elderly the smallest. With discounting, however, the situation is reversed. Much of the health improvements during the past twenty years result from improved cardiovascular health. Cardiovascular disease is of large and immediate importance to the elderly but has a smaller and greatly delayed impact on the young. How much we discount the future has a direct effect on the value of this change. As the discount rate rises, the value of cardiovascular disease improvement to the young falls.

People's health has improved by more than per capita spending on medical care has increased. This statement is not causal; we do not attribute all of the health improvements we measure to medical care (although some are certainly the result of improved medical care). But these results indicate that the rate of return to medical care is not obviously of such low value that people should clearly spend less on it than they do now.

Over the longer term, blacks have improved in health relative to whites, although in the 1980s, blacks-particularly black males-fared somewhat worse than whites. Our data do not give clear evidence on female-male health capital changes.

Our analysis opens up many questions as well. Changes in health 
will almost certainly change people's retirement and savings behavior. People who are healthier may decide to work longer, or they may work less if the healthy elderly can consume leisure activities that the less healthy elderly cannot. Changes in health and the induced retirement effect will, in turn, affect the need for savings for old age. One question our analysis can address is whether the improvements in health we have seen can help explain the broad trends in economic life of the elderly that have been observed over the past half century.

Our analysis can also be used to address fundamental questions about the value of the medical care system and the proper allocation of government funds. For example, the value of remaining quality-adjusted life for a 20 -year-old is about $\$ 2$ million (using the 3 percent discount rate). Each year, about 5,000 young men die of AIDS. Thus, this simple calculation implies that the annual return to eliminating AIDS would be about $\$ 10$ billion. One could compare this number to the treatment costs for AIDS or the costs of research to eliminate AIDS. More generally, this methodology can be used to rank different diseases: How important are they to limited health? How much money would it be worth to eradicate them? Where should public research dollars be spent? We consider these questions among the most fruitful avenues for future research.

\section{References}

Agency for Health Care Policy and Research. 1987. National Medical Expenditure Survey. Rockville, Md.: U.S. Department of Health and Human Services. Ann Arbor, Mich.: Inter-university Consortium for Political and Social Research.

Atkinson, Anthony B., and Joseph E. Stiglitz. 1980. Lectures on Public Economics. McGraw-Hill.

Becker, Gary S. 1975. Human Capital: A Theoretical and Empirical Analysis with Special Reference to Education. Columbia University Press.

Bell, Felicitie C., and Rizie Kumar. 1996. Social Security Area Population Projections: 1996. Actuarial Study 110. Baltimore, Md.: U.S. Social Security Administration, Office of the Actuary.

Bell, Felicitie C., Alice H. Wade, and Stephen C. Gross. 1992. Life Tables for the United States Social Security Area 1900-2080. Actuarial Study 107. Baltimore, Md.: U.S. Social Security Administration, Office of the Actuary. 
Blazer, Dan G., and others. 1994. "The Prevalence and Distribution of Major Depression in a National Community Sample: The National Comorbidity Survey." American Journal of Psychiatry 151 (7): 979-86.

Burke, G. L., and others. 1989. "Trends in CHD Mortality, Morbidity, and Risk Factor Levels from 1960 to 1986: The Minnesota Heart Survey." International Journal of Epidemiology 18 (Supp. 1): S73-S81.

Center for Health Administration Studies, and the National Opinion Research Center. 1970. Survey of Health Services Utilization and Expenditures. Ann Arbor, Mich.: Inter-univeristy Consortium for Political and Social Research.

Chassin, Mark, and others. 1987. "Does Inappropriate Use Explain Geographic Variations in the Use of Health Care Services?' Journal of the American Medical Association 258: 2533-37.

Chirikos, Thomas N. 1986. "Accounting for the Historical Rise in WorkDisability Prevalence."' The Milbank Quarterly 64: 271-301.

Colvez, A., and M. Blanchet. 1981. "Disability Trends in the United States Population 1966-76: Analysis of Reported Causes." American Journal of Public Health 71: 464-71.

Costa, Dora L., and Richard H. Steckel. 1995. Long-Term Trends in Health, Welfare, and Economic Growth in the United States. NBER Historical Working Paper 76. Cambridge, Mass.: National Bureau of Economic Research.

Crimmins, Eileen M. 1990. "Are Americans Healthier as Well as LongerLived?' Journal of Insurance Medicine 22: 89-92.

Cutler, David M. 1995. "The Incidence of Adverse Medical Outcomes under Prospective Payment." Econometrica (February): 29-50.

Cutler, David M., and others. 1996. Are Medical Prices Declining? NBER Working Paper 5750. Cambridge, Mass.: National Bureau of Economic Research. September.

Cutler, David M., and Ellen Meara. 1997. The Medical Costs of the Young and Old: A Forty Year Perspective. NBER Working Paper 6114. Cambridge, Mass.: National Bureau of Economic Research. July.

Cutler, David M., and Doug Staiger. 1996. "Measuring the Benefits of Medical Progress.' Harvard University.

Dardis, Rachel. 1980. "The Value of a Life: New Evidence from the Marketplace." American Economic Review 70: 1077-82.

Deaton, Angus, and Christina Paxson. 1997. "Health, Income, and Inequality over the Life-Cycle." Princeton University.

Demirovic, Jasenka, and others. 1993. "Sex Differences in Coronary Heart Disease Mortality Trends: The Minnesota Heart Survey, 1970-1988." Epidemiology 4: 79-82.

Doliszny, Katherine, and others. 1994. "Estimated Contribution of Coronary Artery Bypass Graft Surgery to the Decline in Coronary Heart Disease Mor- 
tality: The Minnesota Heart Survey." Journal of the American College of Cardiology 24: 95-103.

Dubos, René. 1969. "The Diseases of Civilization." Milbank Memorial Fund Quarterly 47: 327-39.

Epstein, Arnold M., and others. 1989. “Using Proxies to Evaluate Quality of Life: Can They Provide Valid Information about Patients' Health Status and Satisfaction with Medical Care?" Medical Care 27 (Supp.): S91-S98.

Ernster, Virginia L., and others. 1996. "Incidence of and Treatment for Ductal Carcinoma in Situ of the Breast." Journal of the American Medical Association 275: 913-18.

Fogel, Robert W., Dora L. Costa, and John M. Kim. 1993. "Secular Trends in the Distribution of Chronic Conditions and Disabilities at Young Adult and Late Ages, 1960-1988: Some Preliminary Findings." University of Chicago.

Frank, Richard, and Ernst Berndt. 1997. "Prices for Treatment of Depression." Harvard University.

Fryback, Dennis G., and others. 1993. "The Beaver Dam Health Outcomes Study: Initial Catalog of Health-State Quality Factors." Medical Decision Making 13: 89-102.

Fuchs, Victor R. 1982. "Time Preference and Health: An Exploratory Study." In Economic Aspects of Health, edited by Victor R. Fuchs. University of Chicago Press.

Gold, M.R., and others. 1996. Cost-Effectiveness in Health and Medicine. Oxford University Press.

Gomez-Marin, Orlando, and others. 1987. "Improvement in Long-Term Survival among Patients Hospitalized with Acute Myocardial Infarction, 1970 to 1980." New England Journal of Medicine 316: 1353-59.

Greenspan, Allan M., and others. 1988. "Incidence of Unwarranted Implantation of Permanent Cardiac Pacemakers in a Large Medical Population." New England Journal of Medicine 318: 158-63.

Grossman, Michael. 1972. The Demand for Health: A Theoretical and Empirical Investigation. Columbia University Press.

Higgins, Millicent, and Thomas J. Thom. 1993. “Trends in Stroke Risk Factors in the United States." Annals of Epidemiology 3: 550-54.

Ho, Kalon K. L., and others. 1993. "Survival after the Onset of Congestive Heart Failure in Framingham Heart Study Subjects." Circulation 88: 10715.

Hunink, Maria G. M., and others. 1997. "The Recent Decline in Mortality from Coronary Heart Disease, 1980-1990: The Effect of Secular Trends in Risk Factors and Assessment." Journal of the American Medical Association 277: 535-42.

Idler, Ellen L., and Stanislav V. Kasl. 1995. “'Self-Ratings of Health: Do They 
Also Predict Change in Functional Ability?' Journals of Gerontology 50: S344-53.

Johannesson, Magnus. 1996. "A Note on the Relationship between Ex-Ante and Expected Willingness to Pay for Health Care." Social Science and Medicine 42: 305-11.

Kahn, Katherine L., and others. 1990. "Comparing Outcomes of Care before and after Implementation of the DRG-Based Prospective Payment System." Journal of the American Medical Association 264: 1984-88.

Karoly, Lynn, and Gary Burtless. 1995. "Demographic Change, Rising Earnings Inequality, and the Distribution of Personal Well-Being, 1959-1989." Demography 32: 379-407.

Larson, Martin G. 1995. "Assessment of Cardiovascular Risk Factors in the Elderly: The Framingham Heart Study." Statistics in Medicine 14: 174556.

Manton, Kenneth G., Larry Corder, and Eric Stallard. 1997. "Chronic Disability Trends in Elderly United States Populations: 1982-1994." Proceedings of the National Academy of Sciences 94: 2593-98.

McClellan, Mark, and Joseph P. Newhouse. 1995. "The Marginal Benefits of Medical Technology." Harvard University.

McGovern, Paul G., and others. 1992. "Trends in Survival of Hospitalized Myocardial Infarction Patients between 1970 and 1985: The Minnesota Heart Survey." Circulation 85: 172-79.

McGovern, Paul G., and others. 1993. "The Role of Stroke Attack Rate and Case Fatality in the Decline of Stroke Mortality: The Minnesota Heart Survey." Annals of Epidemiology 3: 483-87.

McGovern, Paul G., and others. 1996. "Recent Trends in Acute Coronary Heart Disease: Mortality, Morbidity, Medical Care, and Risk Factors." New England Journal of Medicine 334: 884-90.

Moore, Michael J., and W. Kip Viscusi. 1988. "The Quantity-Adjusted Value of Life." Economic Inquiry 26: 369-88.

Murray, Christopher J. L., and Alan D. Lopez, eds. 1996. The Global Burden of Disease: A Comprehensive Assessment of Mortality and Disability from Diseases, Injuries, and Risk Factors in 1990 and Projected to 2020. Harvard University Press.

Najman, J. M., and S. Levine. 1981. "Evaluating the Impact of Medical Care and Technologies on the Quality of Life: A Review and Critique." Social Science \& Medicine 15: 107-15.

National Cancer Institute. 1994. SEER Cancer Statistics Review (1973-1991). U.S. Department of Health and Human Services, Public Health Service, National Institutes of Health, Washington, D.C.

National Center for Health Services Research. 1977. National Medical Care Expenditure Survey. Hyattsville, Md.: U.S. Department of Health and Hu- 
man Services; Ann Arbor, Mich.: Inter-university Consortium for Political and Social Research.

National Center for Health Statistics. 1969-93. National Health Interview Survey. Hyattsville, Md.: U.S. Department of Health and Human Services, Ann Arbor, Mich.: Inter-university Consortium for Political and Social Research.

Neumann, Peter J., and Magnus Johannesson. 1994. "The Willingness to Pay for In-Vitro Fertilization: A Pilot Study Using Contingent Valuation." Medical Care 32: 686-99.

Neumann, Peter J., Darren E. Zinner, and Janice Wright. Forthcoming. " Are Methods for Estimating QALYS Improving?' Medical Decision Making.

Newhouse, Joseph P., and the Insurance Experiment Group. 1993. Free for All?: Lessons from the Rand Health Insurance Experiment. Harvard University Press.

O'Brien, Bernie, and Jose Luis Viramontes. 1994. "Willingness to Pay: A Valid and Reliable Measure of Health State Preference?"' Medical Decision Making 14: 289-97.

Pell, Sidney, and William E. Fayerweather. 1985. "Trends in the Incidence of Myocardial Infarction and in Associated Mortality and Morbidity in a Large Employed Population, 1957-1983." New England Journal of Medicine 312: 1005-11.

Preston, Samuel H., and Michael R. Haines. 1991. Fatal Years: Child Mortality in Late Nineteenth-Century America. Princeton University Press.

Ramsey, Frank R. 1927. "A Contribution to the Theory of Taxation." Economic Journal 37: 47-61.

Robins, Lee N., and others. 1984. "Lifetime Prevalence of Specific Psychiatric Disorders in Three Sites." Archives of General Psychiatry 41: 949-58.

Sackett, David L., and George W. Torrance. 1978. "The Utility of Different Health States as Perceived by the General Public." Journal of Chronic Diseases 31: 697-704.

Schauffler, Helen Halpin, and others. 1993. "Risk for Cardiovascular Disease in the Elderly and Associated Medicare Costs: The Framingham Study." American Journal of Preventive Medicine 9: 146-54.

Somervell, Philip D., and others. 1989. "The Prevalence of Major Depression in Black and White Adults in Five United States Communities." American Journal of Epidemiology 130: 725-35.

Staiger, Douglas, and Gary Gaumer. 1994. "Prospective Payment and Hospital Mortality." Harvard University.

Sytkowski, Pamela A., and others. 1990. "Changes in Risk Factors and the Decline in Mortality from Cardiovascular Disease." New England Journal of Medicine 322: 1635-41.

Sytkowski, Pamela A., and others. 1996. "Sex and Time Trends in Cardio- 
vascular Disease Incidence and Mortality: The Framingham Heart Study, 1950-1989." American Journal of Epidemiology 143: 338-50.

Tolley, George S., Donald Scott Kenkel, and Robert G. Fabian, eds. 1994. Valuing Health for Policy: An Economic Approach. University of Chicago Press.

Torrance, George W. 1986. "Measurement of Health State Utilities for Economic Appraisal." Journal of Health Economics 5: 1-30.

Tu, Jack V., and others. 1997. "Use of Cardiac Procedures and Outcomes in Elderly Patients with Myocardial Infarction in the United States and Canada."' New England Journal of Medicine 336: 1500-05.

Verbrugge, Lois M. 1984. "Longer Life But Worsening Health? Trends in Health and Mortality of Middle-Aged and Older Persons." Milbank Memorial Fund Quarterly: Health and Society 62: 475-519.

Viscusi, W. Kip. 1993. "The Value of Risks to Life and Health." Journal of Economic Literature 31: 1912-46.

Waidmann, Timothy, John Bound, and Michael Schoenbaum. 1995. "The Illusion of Failure: Trends in the Self-Reported Health of the U.S. Elderly.", The Milbank Quarterly 73: 253-87.

Wickramaratne, Priya J., and others. 1989. “Age, Period, and Cohort Effects on the Risk of Major Depression: Results from Five United States Communities." Journal of Clinical Epidemiology 42(4): 333-43.

Winslow, Constance M., Jacqueline B. Kosecoff, and others. 1988. "The Appropriateness of Performing Coronary Artery Bypass Surgery." Journal of the American Medical Association 260: 505-10.

Winslow, Constance M., David H. Solomon, and others. 1988. "The Appropriateness of Carotid Endarterectomy." New England Journal of Medicine 318: 721-27. 


\section{Comments}

Comment by Theodore E. Keeler: This is an interesting and important paper because it opens up a new way of looking at health in economic terms, both over time and across populations. I have two sets of comments: The first relates to the construction of the index of health capital as the authors have done it; the second relates to one intended use of that series (begun in the paper but really the subject of further research): analysis of the contribution of medical care in the United States to improved health over time.

\section{Construction of the Series}

One set of numbers on which the authors' results would seem to depend rather crucially is the set of period life tables from the Social Security Administration used to calculate the probability of a particular individual dying at each age in each year. At values of life of $\$ 100,000$ per year, what might seem to be small variations in the figures in these life tables in a given year can make for substantial differences in the estimate of aggregate health capital stocks. If this is so, one would want to be aware of any possible biases in the life tables.

Any such biases are likely to be complicated. Mortality tables come from estimating deaths as a percentage of a given population. Deaths are generally well reported; it is more likely that the denominator of deaths in the life table, the population in a given age group, may get misreported, so the bigger question is what is happening to the "uncounted" population (if one exists) in each age group over time. It is difficult to believe such counting problems are likely to be large, but 
controversy continues about whether some elements of the population are indeed uncounted. In any event, it pays to be aware of these kinds of potential problems with the data.

A second concern relates to the quality adjustments for the qualityadjusted life years capital stock. The use of the National Health Interview Survey data to determine the effects of chronic illness on wellbeing is clever. The illnesses included here are obviously determined to a large degree by data availability. But I do wonder whether the results might be biased by some of the illnesses excluded. For example, people who either have or are trying to avoid HIV probably have had their quality of life affected by it, and HIV is not one of the illnesses included in the quality of life analysis.

Third, although many of the changes in quality of life associated with improved health are unambiguously utility increasing (as they are treated by Cutler and Richardson), not all of them are. For example, those people who truly enjoy smoking, but quit in order to live longer, will suffer reduced utility. Because many have quit smoking over the past decades, this change will cause the utility of those people to fall, and that change is not included in Cutler and Richardson's quality of life years measure. Similar effects will be found by those who find they must alter their diets, alcohol consumption, or even sex lives in the interest of better health. Finding data needed to incorporate these changes of utility into the QALY health capital stock estimates is admittedly difficult or impossible, but their exclusion does represent a likely bias in Cutler and Richardson's results toward overestimating improvements in quality of life over time.

My fourth comment on the construction of the series concerns behavioral risk factors, such as smoking or seat belt use in cars. Equation 2 treats these as consumption decisions that affect health capital through the production function for health, that is, as inputs to the production of health. The authors argue that risk factors should be included as part of the measure of the stock itself, that is, as outputs to the health production process. They cannot be both, they should be one or the other, and it makes much more sense to include them as inputs that determine the stock, rather than the stock. That is what the authors have done, and I am not sure why they apologize for it or why they resolve to include the factors in subsequent measures of health capital (nonbehavioral risk factors, such as hypertension and obesity, however, 
might be different). It is conceptually important to distinguish between inputs and outputs in the health production process.

\section{Use of the Health Capital Stock Series}

The main purpose of the paper is to show the building of a health capital stock series and to set forth the rationale behind it. But few economic statistics can stand as meaningful, independent of their future use or the hypotheses to be tested with them. One important planned use of the estimated health capital series (noted in the final paragraph of the paper) is to estimate the contribution of medical care to health improvements and to determine whether too much or too little medical care (on the margin) of various types is being provided.

I suspect the authors are aware of the difficulty of this task, but I cannot resist pointing out some of the pitfalls in this area, as well as how readily the data they have already developed could be misinterpreted. As Cutler and Richardson state at the beginning, many analyses of U.S. health care have assumed the marginal product of medical care is near zero. This assumption is not drawn from a vacuum: Numerous attempts have been made to estimate a production function for health.' There have also been more qualitative analyses that are widely believed to have shed light on this issue. ${ }^{2}$ The empirical conclusion has almost always been that the marginal product of medical care is indeed low. Furthermore, the notion that the marginal product of medical care in improving health in the United States is very low (at least for the insured) is also consistent with the view that the marginal cost of medical care to a typical user, because of health insurance, is also very low, providing an incentive to use it to the point that the marginal product is low. Cutler and Richardson's study, which at least tentatively finds otherwise, will thus challenge conventional wisdom. The authors are careful to stop short of claiming that observed improvements in health are largely attributed to medical care, yet they indicate in places that their data support the view that medical care is important on the margin in determining U.S. health levels.

Indeed, Cutler and Richardson provide the beginnings of the needed analysis by comparing the improvements in the per capital health capital

1. One of the earliest was Auster, Leveson, and Sarachek (1969).

2. Most importantly, see Fuchs (1986). 
stock between 1970 and 1990 with changes in expected medical expenditures over a lifetime in constant dollars in the same two years. They find that the (years-of-life-based) health capital stock increased much more rapidly (by $\$ 77,000$ at a 3 percent discount rate for an infant, for example; see table 1) than the expected medical care expenditures did (by $\$ 19,000$ for an infant with the same discount rate) over nearly the same period (table 4). Although qualifying their conclusions appropriately, Cutler and Richardson comment that it is at least possible (perhaps likely) that the increased medical care expenditures over the period were justified by the improved health that they bought.

I have no objection to any of this, but comparison of the benefits and costs of medical care along these lines raises some serious questions, especially concerning any hypothesized relationship between medical expenditures and health levels. For example, if we are to infer a relationship between medical care and health capital, over what period and with what lags should we specify the relationship? It is at least worth speculating that data analysis for the 1940s (when effective use of antibiotics was growing rapidly) and the 1970s (with the improvements in cardiovascular care) would show a very strong positive role for medical care in improving health. Analysis for other periods might not show medical care in such a favorable light, but long and variable lags could make it difficult to identify the analytical relationships needed in order to understand proper allocation of medical care resources. All this means that using aggregate stocks of health to measure either econometric or "growth accounting" relationships between medical inputs and health stock outputs may be very difficult, indeed.

Furthermore, in the context of the production function for health, it will be important to determine which changes represent movements of isoquants that do not require more expenditure (although they might require more research) versus those benefits that require additional capital expenditure to realize. Thus, even though health care expenditures increased substantially during the 1970s, and so did benefits in health capital, it may not have been necessary to make the increased expenditures to get the improvements in cardiac care. The macro numbers could be hiding micro processes that could not be understood without substantial disaggregation.

None of this is to detract from what Cutler and Richardson have achieved so far. Indeed, the framework they have set up can be quite 
valuable in helping us understand what we do and do not know. Their concepts and figures are clearly useful, but they must be used with great care.

Comment by Douglas Staiger: In the last half century extraordinary advances have been made in the understanding and treatment of human disease, spanning topics ranging from diet to organ transplantation. Yet at the same time, the share of gross domestic product (GDP) being spent on health care has roughly tripled, going from 5 percent in 1960 to nearly 14 percent in 1995 . Although great detail is known about the rise in health expenditures, relatively little is known about the benefits of these medical advances. How much have they improved well-being? Which years experienced the largest improvements in health? What have been the distributional impacts of these medical advances?

This ambitious paper sets out to answer these questions. This is a daunting task, for as the title suggests, it requires no less than measuring the health of the U.S. population. In the tradition of many great papers in public finance, Cutler and Richardson make a broad-brush attempt to quantify the value of health improvements over the last forty years. The most striking feature of their answer is its magnitude. For example, they estimate that the value of health improvements between 1970 and 1990 was roughly five times larger than the increase in medical spending in this same period, with the largest improvements occurring among blacks, the elderly, and men. Although one may quibble with many of the details in their analysis, the ultimate goal of their work is to gain some idea of the order of magnitude of the answers to the questions posed above. Thus, as Gary Becker did in his early work on human capital, this paper lays out a general framework for thinking about improvements in health and leaves the more problematic details to future work.

One of the strengths of this paper is that the authors are very clear about what is being measured. The key equations defining "health capital" are their equations 5 and 6 . By analogy to human capital, a change in health capital is measured as the net present value of the change in payoff streams over the remainder of a person's life. The only difficulty is that health (unlike earnings) is not naturally reported in dollars. Therefore a change in health is valued as the wealth (or, equivalently, the present-day value of consumption) that a person would 
be willing to give up in exchange for a given change in health over the remainder of his or her lifetime. So, for example, an increase in health capital of approximately $\$ 100,000$ between 1970 and 1990 means I would give up roughly $\$ 3,500$ a year in consumption over my entire lifetime to go from the health observed in 1970 to that observed in 1990. This is an astoundingly large estimate, equivalent to roughly 20 percent of per capita disposable income in 1990 and to more than half of the rise in per capita disposable income between 1970 and 1990 .

In principle, what are these estimates useful for? The authors use them in two ways. First for a kind of macro-level cost-benefit analysis, comparing the costs of improving health with these measured benefits and then computing a return to investments in health capital. Unfortunately, it is nearly impossible to estimate the costs involved. For example, the improvement in health outcomes between 1970 and 1990 was the result not only of medical care, but also of lifestyle changes such as improvements in diet and reduced smoking. I think it would be quite difficult to place dollar values on such things as having cream in my coffee, butter on my bread, or a cigarette. Moreover, doing such a cost-benefit analysis at older ages (for example, age 65) is even more problematic because much of the improvement in health after age 65 may be the result of investments in health made before age 65 .

A second use for these estimates of health capital, and the use I think is most appropriate, is for evaluating the distributional consequences of improvements in health. Much has been written about changes in the earnings distribution during the last two decades. Returns to education have increased, for example, while the male-female and black-white wage gaps have narrowed. How do the changes in health capital estimated in this paper compare to changes in "labor market" capital, as reflected in earnings?

In table 1 , I compare changes in health capital as estimated by Cutler and Richardson to a measure of labor market capital that I have constructed from Current Population Survey (CPS) data. To construct a measure of labor market capital, I made a calculation analogous to that used for health capital. First, I estimated average hourly wages by single year of age in 1973 and 1990, using data on all individuals working at least eight hours a week from the May 1972 CPS and the 1990 merged outgoing rotation groups of the CPS. The 1973 wages were inflated to 1990 dollars using the CPI-U X1 (a version of the consumer price index 
Table 1. Comparison of Health and "Labor Market" Capital at Age 0 1990 dollars

\begin{tabular}{|c|c|c|c|c|}
\hline \multirow[b]{2}{*}{ Group } & \multicolumn{2}{|c|}{$\begin{array}{c}\text { Health capital } \\
(Q A L Y S) \text { at age } 0\end{array}$} & \multicolumn{2}{|c|}{$\begin{array}{l}\text { "Labor market" } \\
\text { capital at age } 0\end{array}$} \\
\hline & $\begin{array}{c}\text { Level in } \\
1970\end{array}$ & $\begin{array}{l}\text { Change } \\
1970-90\end{array}$ & $\begin{array}{c}\text { Level in } \\
1970\end{array}$ & $\begin{array}{l}\text { Change } \\
1970-90\end{array}$ \\
\hline All & 2,350 & 95 & 333 & -29 \\
\hline \multicolumn{5}{|l|}{ Men } \\
\hline White & 2,364 & 108 & 393 & -41 \\
\hline Black & 2,225 & 122 & 316 & -20 \\
\hline \multicolumn{5}{|l|}{ Women } \\
\hline White & 2,348 & 89 & 254 & 7 \\
\hline Black & 2,226 & 135 & 232 & 14 \\
\hline
\end{tabular}

Sources: Health capital from tables 11 and 12 in Cutler and Richardson. "Labor market" capital based on expected present value of earnings assuming all individuals work 2.000 hours per year from age 18 to 65 . Average hourly wages by age in 1973 and in 1990 are estimated from the 1973 May CPS. and the 1990 Merged Outgoing Rotation Groups of the CPS. using all individuals working at least 8 hours per week. Wages in 1973 were inflated to 1990 dollars using the CPI-U $\mathrm{XI}$. The discount rate is 3 percent.

for all urban consumers that treats housing consistently over time). Finally I computed labor market capital at age 0 as the present discounted value of earnings assuming that an individual works 2,000 hours a year from age 18 to age 65 . These calculations are done in aggregate and then separately by gender and race.

The estimates in table 1 again highlight that the estimated changes in health capital between 1970 and 1990 are very large. The gains in health capital swamp the declines in earnings experienced during this period, particularly for men. In comparing demographic groups, health capital appears to amplify the changes that were going on in the labor market among blacks, but not as clearly among women. In particular, some of the labor market gains among white women seem to be offset by their having a smaller increase in health capital compared with other groups. Why this might be the case seems like an interesting question for future work.

Why are these changes in health capital so large? Part of the reason is mechanical: The changes are working off a larger base. The health capital calculation assumed each healthy year is worth $\$ 100,000$. This is far more than per capita income or consumption, so the level of health capital in 1970 is large relative to the present-day value of labor market earnings or consumption. As a result, although the changes in 
health capital in table 1 are larger absolutely than the changes in labor market capital, they tend to be smaller proportionately. Whether one agrees or not with the specifics of Cutler and Richardson's calculations, it is clear that changes in health capital have potentially very large welfare effects, because a 5 percent change in health capital is equivalent to a roughly 30 percent change in earnings.

Of course, this same line of argument implies that the specifics of the health capital calculation are quite important, because an error of 1 or 2 percent has enormous consequences for the absolute change in health capital. Three key factors drive the estimated changes in health capital between 1970 and 1990: declining mortality at older ages; an increase in the probability of disease at a given age; and an increase in the estimated QALY (quality-adjusted life years) given a person's disease and age. Thus the key question is the reliability of the estimates of these three components.

The first component, declining mortality between 1970 and 1990, seems uncontroversial. The exact magnitude of this decline is more debatable, however. The authors estimate this decline by comparing the cross-section relation between age and mortality in 1970 to that in 1990. Of course, the cross-section relationship in any period is not likely to be representative of the mortality profile that people expect over the remainder of their lives. For example, I would think that current 20-year-olds may expect lower mortality at age 70 than current 70 -year-olds because of better nutrition while they were children. This problem is analogous to that of using cross-section wage-age profiles as estimates of future wages, that is, cohort and age effects are not separately identified. Future work may be better able to untangle these age, time, and cohort effects. For the present, it seems reasonable to assume that both the 1970 and 1990 mortality estimates will tend to overstate expected mortality, and as a result understate the level of health capital in any given year. There is no obvious bias, however, in the estimates of the change in health capital.

The second component is an increase in the probability of disease at a given age. Obviously the key issue here is the increased reporting and detecting of disease over time, which would tend to understate the rise in health capital. Although this is a difficult problem to address, Cutler and Richardson develop a novel solution. Rather than try to adjust the disease rates for over-reporting, they simply define QALYs in terms of 
reported disease. In fact, one of the major advantages of their method for measuring QALYs is that it is based on self-reported disease and health status, so that if reporting rates increase for a given disease, the estimated QALY can adjust to reflect this.

The final component, and the one I think is most problematic, is an increase in the estimated QALY given a person's disease and age. This is the key to the estimated increase in health capital between 1970 and 1990. As Cutler and Richardson show in table 13, if QALYs had not increased, then the gain in health capital would have been close to zero. In many ways the QALY scale plays the role of prices, and increases over time in the QALY scale are like changes in the CPI. It should not be surprising that the deflator used can affect the answer. For example, the overall decline in labor market capital calculated in my table 1 would have been nearly twice as large had I used the CPI-U deflator (which treats housing inconsistently over this period). At the same time, it is less clear that the estimated increase in QALYs is so important for distributional questions. For example, if one estimated a smaller increase in QALYs, it could simply rescale the change in health capital for all the demographic groups and leave their relative positions intact.

Unfortunately the data in this paper provide no obvious way to confirm that QALYs increased over time. The self-reported health question that Cutler and Richardson use to estimate QALYs in 1970 and 1990 provides no natural scale that can be compared across time. The question asks respondents to rate their health status relative to others their own age. Thus, an overall improvement in the health status of the population could, in principle, have no effect on self-reported health. At best one can hope to use these measures to produce an index that ranks individuals according to health status in 1970 and 1990. The problem then, however, is how to scale these two indexes. Cutler and Richardson assume that the distance between cutoffs in an ordered probit between the borders of the top and bottom categories correspond to one QALY, and a person with no disease is assigned a QALY of 1. There is little justification for this ad hoc approach, because there is no reason to think that QALYs are always 1 for a person without disease or that the distance between excellent and poor health has remained constant over time. One alternative method would be to find conditions that one could safely assume had not changed their QALY values over time and use these conditions to norm the 1970 and 1990 scales. An- 
other alternative would be to develop a self-reported health measure that had an absolute (rather than relative) scale. It is not obvious that either of these alternatives is practical, but at least they have the advantage of being less ad hoc.

Measuring QALYs is central to answering the question this paper asks: Can we measure the value of health and how it changes over time? At the very least, how sensitive are these estimates to alternative methods of measuring QALYs? This should be a high priority for future work on this topic.

\section{Commentators' References}

Auster, Richard D., Irving Leveson, and Deborah Sarachek. 1969. "The Production of Health: An Exploratory Study." Journal of Human Resources 4 (Fall): 411-36.

Fuchs, Victor R. 1986. "Some Economic Aspects of Mortality in Developed Countries." In The Health Economy, edited by Victor R. Fuchs. Harvard University Press. 